\title{
HP1 $\beta$ Chromo Shadow Domain facilitates H2A ubiquitination for BRCA1 recruitment at DNA double-strand breaks
}

\author{
${ }^{1}$ Vijaya Charaka, ${ }^{1}$ Sharmista Chakraborty, ${ }^{2}$ Chi-Lin Tsai, ${ }^{2}$ Xiaoyan Wang, ${ }^{1,3}$ Raj K \\ Pandita, ${ }^{2}$ John A. Tainer, ${ }^{1}$ Clayton R Hunt and ${ }^{1,3,4}$ Tej K. Pandita \\ 1Department of Radiation Oncology, The Houston Methodist Research Institute, \\ Houston TX 77030, USA; '2Department of Molecular and Cellular Oncology, The \\ University of Texas MD Anderson Cancer Center, Houston, TX 77030, USA; \\ ${ }^{13}$ Department of Molecular and Cellular Biology, Baylor College of Medicine, \\ Houston, TX 77030, USA; ${ }^{4}$ Center for Genomics and Precision Medicine, Texas \\ A\&M College of Medicine, Houston, Texas, USA
}

Running title: HP1 $\beta$ promotes BRCA1 recruitment

Key words: HP1 $\beta$, chromo shadow domain, BRCA1, ubiquitination, homologous recombination

\section{Authors e-mail address:}

Vijay K. Charaka: vkcharaka@houstonmethodist.org

Sharmistha Chakraborty: sharmisthachakraborty70@gmail.com

Chi Lin Tsai:

ctsai5@mdanderson.org

Xiaoyan Wang:

Raj K. Pandita:

John A. Tainer:

Clayton R Hunt:

xiaoyan.wang2016@outlook.com

rkp_jalali@yahoo.com

jtainer@mdanderson.org

Tej K. Pandita:

crhunt305@gmail.com

tejkrishnanpandita@gmail.com;

tej.pandita@BCM.edu; tpandita@tamu.edu

\section{Authors have no conflict of interest}

${ }^{*}$ Correspondence:

Tej K. Pandita

E-mail: tejkrishnanpandita@gmail.com

Phone: 1-832-982-7073; 1-713-677-7602 


\section{Abstract:}

Efficient DNA double strand break (DSB) repair by homologous recombination $(\mathrm{HR})$, as orchestrated by histone and non-histone proteins, is critical to genome stability, replication, transcription, and cancer avoidance. Here we report that Heterochromatin Protein1 beta (HP1 $\beta)$ acts as a key component of the HR DNA resection step by regulating BRCA1 enrichment at DNA damage sites, a function largely dependent on the HP1 $1 \beta$ chromo shadow domain (CSD). HP1 $\beta$ itself is enriched at-DSBs within gene-rich regions through a CSD interaction with Chromatin Assembly Factor 1 (CAF1) and HP1 $\beta$ depletion impairs subsequent BRCA1 enrichment. An added interaction of the HP1 $\beta$ CSD with the Polycomb Repressor Complex 1 ubiquitinase component RING1A facilitates BRCA1 recruitment by increasing $\mathrm{H} 2 \mathrm{~A}$ lysine 118-119 ubiquitination, a marker for BRCA1 recruitment. Our findings reveal that HP1 $\beta$ interactions, mediated through its CSD with RING1A, promote $\mathrm{H} 2 \mathrm{~A}$ ubiquitination and facilitate BRCA1 recruitment at DNA damage sites, a critical step in DSB repair by the HR pathway. These collective results unveil how HP1 $\beta$ is recruited to DSBs in gene-rich regions and how HP1 $\beta$ subsequently promotes BRCA1 recruitment to further HR DNA damage repair by stimulating CtIP-dependent resection. 


\section{Introduction:}

In eukaryotes, genomic DNA is associated with histone and non-histone proteins, that provide the chromatin organization required to regulate transcription, replication, recombination, and DNA repair (Finn and Misteli, 2019; Hunt et al., 2013; Kumar et al., 2012; Pandita and Richardson, 2009; Serizay and Ahringer, 2018). Disturbances in chromatin structure and remodeling are, therefore, often associated with cancer development and progression (Singh et al., 2000; Zhao et al., 2021). Chromatin structure is modulated further by post-translational modifications to the associated proteins (phosphorylation, acetylation, and ubiquitination among others). These modifications can dynamically regulate subsequent recruitment of factors required to initiate a wide range of molecular processes, including the proteins necessary for repair of DNA damage sites (Bennett et al., 2013; Georgoulis et al., 2017; Guo et al., 2018; Hunt et al., 2013; Kaidi et al., 2010; Li et al., 2018; Mendez-Acuna et al., 2010; Shima et al., 2013). At DNA damage sites, histone $\mathrm{H} 2 \mathrm{AX}$ is rapidly phosphorylated $(\mathrm{\gamma}-\mathrm{H} 2 \mathrm{AX})$ to act as a marker signaling DNA damage and also aids repair factor recruitment (Horikoshi et al., 2016; Mujoo et al., 2017; Scully and Xie, 2013; Williams et al., 2010; Xie et al., 2010; Yuan and Chen, 2010). Preexisting chromatin modifications also play an important role in the DNA damage response (DDR), for example methylation at H4K20 is essential for 53BP1 foci formation (Kakarougkas et al., 2013; Svobodova Kovarikova et al., 2018) and H4K16ac in transcribing regions is critical for DSB repair by homologous recombination (Horikoshi et al., 2019). Methylation at H3K4 and H3K79 in transcribing regions drives non-homologous end joining (NHEJ) 
mediated DNA double strand break (DSB) repair (Wei et al., 2018). H3K36 methylation is implicated in DNA repair pathway choice by enhancing the association of the MRN complex to promote NHEJ as well as recruitment of NBS1 through its BRCT2 domain (Fnu et al., 2011).

Methylated histone H3K9 serves as a binding site for isoforms of HP1 (HP1a, HP1 $\beta$ and HP1Y) that are important for heterochromatin formation. All three HP1 isoforms have a related overall structure, an N-terminal chromodomain (CD) sequence, which is responsible for $\mathrm{H} 3 \mathrm{~K} 9 \mathrm{me} 2$ binding, connected by a hinge region to a variable $\mathrm{C}$-terminal chromoshadow domain (CSD). Depletion of HP1 $\beta$ induces genomic instability (Aucott et al., 2008), though the mechanism is unclear. After DSB formation, $\mathrm{HP} 1 \beta$ or $\mathrm{H} 3 \mathrm{~K} 9 \mathrm{me} 2$ are enriched at the break sites and help recruit additional DNA compacting proteins, like suv39H1, which further increase H3K9me2 and HP1 $\beta$ around the sites, leading to gene silencing (Chaturvedi et al., 2012). Moreover, HP1 $\beta$ also plays an important role in DSB repair by HR, as HP1 $\beta$ depletion decreased repair foci formation (Ayoub et al., 2008; Ball and Yokomori, 2009) including those foci containing the important HR repair factor BRCA1 (Lee et al., 2013). Here we show that following DSB induction, HP1 $\beta$ recruits RING1A which ubiquitinates $\mathrm{H} 2 \mathrm{~A}$ at lysine 118 and 119 , a histone modification needed for BRCA1 recruitment and resection of the DSB site prior to repair by HR. 


\section{Results:}

\section{Radiation sensitivity induced by HP1 $\beta$ depletion is reversed by expression of the HP1 $\beta$ chromoshadow domain (CSD) alone}

To analyze the contribution of individual HP1 $\beta$ domains to a functional DDR, we expressed CSD HP1 (Flag-CSD HP1 $\beta, \Delta$ amino acids 22-79) or CD HP1 (FlagCD HP1 $\beta, \Delta$ amino acids to 117-185) regions (Fig. 1A) in H1299 cells after depletion of endogenous HP1ß by UTR specific siRNA (Fig. 1B). Depletion of HP1 $\beta$ increased cell killing by IR, and was rescued by expression of full length Flag HP1 $1 \beta$ or Flag-CSD but not Flag-CD (Fig. 1C). Depletion of HP1 $\beta$ had minimum effect on the initial appearance of IR-induced $\mathrm{y}-\mathrm{H} 2 \mathrm{AX}$ and 53BP1 foci; however, residual foci after 4 or $8 \mathrm{hr}$ post-irradiation were higher in HP1 $\beta$ depleted cells than in control cells which was rescued by expression of CSD but not CD (Fig. 1D,E, Supplementary Fig. 1A,B). Higher residual $\mathrm{y}-\mathrm{H} 2 \mathrm{AX}$ and 53BP1 foci after DNA damage suggests defective DSB repair (Gupta et al., 2014a; Kumar et al., 2012; Ward et al., 2003). Since radiation damage can be repaired by either NHEJ or HR, we determined which DNA repair pathway(s) were sensitive to HP1 $1 \beta$ depletion.

We ectopically expressed wild-type or HP1 $\beta$ mutants in DR-GFP and EJ5CHIB expressing cell lines (Horikoshi et al., 2019) previously depleted of HP1 $\beta$. Depletion of endogenous HP1 $\beta$ reduced DSB repair by HR as measured in DRGFP cells but expression of either wild type HP1 $\beta$ or the CSD domain alone rescued HR mediated repair. Expression of the CD HP1 $1 \beta$ domain, however, did not rescue HR mediated DSB repair (Fig. 1F). Measurement of NHEJ repair in 
EJ5-CHIB cells indicated HP1 $\beta$ depletion had no significant effect on repair mediated by this pathway (Fig. 1G). The EJ5-CHIB cell assay tests NHEJ at a single, integrated genomic site but identical results were obtained after transient transfection of a linearized NHEJ substrate plasmid template into endogenous HP1 $\beta$ depleted cells (Supplementary Fig. 1C), further confirming HP1 $\beta$ depletion does not impair DSB repair by NHEJ.

\section{CSD HP1 $\beta$ recruitment at DNA damage sites involves CAF1}

During the early DDR response after DNA strand breakage, HP1 $1 \beta$ protein is recruited to break sites to promote H3K9 methylation (Ayrapetov et al., 2014; Zeng et al., 2010). Several reports have shown that HP1 $\beta$ binding to H3K9me2 increases retention of KAP1, and HP1 $\beta$ along with suv39h1 ensure gene silencing during DSB repair (Ayrapetov et al., 2014; Sharma et al., 2003). To examine HP1 $\beta$ recruitment near DNA break sites, three I-Sce1 inducible DSB sites were inserted at different specific positions in the genome (Chr1A, Chr1B and Chr1C) as described (Supplementary Fig. 2A) (Horikoshi et al., 2019) and protein levels at the DSB sites analyzed by ChIP/qPCR (Horikoshi et al., 2019). The Chr1A and Chr1C I-Sce1 sites are in gene rich and H4K16ac high density regions while the Chr1B site is in a gene and H4K16ac poor region (Horikoshi et al., 2019). As expected, both $\mathrm{Y}-\mathrm{H} 2 \mathrm{AX}$ and $\mathrm{HP} 1 \beta$ increased at the Chr1A, Chr1B and Chr1C sites after DSB induction (Fig. 2A, B), but a relatively higher fold enrichment of HP1 $\beta$ in $\mathrm{H} 4 \mathrm{~K} 16 \mathrm{ac}$ rich regions was observed as compared to the H4K16ac poor region (Fig. 2A). Analysis of the individual HP1 $\beta$ CSD and CD domains indicated both were highly enriched at DSBs in gene-rich regions, where HR is known to be 
predominant (Horikoshi et al., 2019) (Fig. 2C, D). In contrast, both HP1ß mutants displayed only a small increase in levels at the gene poor region Chr1B site after DSB induction (Fig. 2C, D).

Previous reports found that repressive marker (HP1 $\beta$ and H3K9me2) enrichment at DNA break sites promoted additional recruitment/marks around the site (Alagoz et al., 2015). We found that H3K9me2 levels increased after DNA damage, but HP1 $\beta$ loss reduced the H3K9me2 levels at the break site (Supplementary Fig. 2B).

Luijsterburg and co-workers suggested that HP1 $\beta$ recruitment is independent of both its CD, which is the methyl-binding domain, and chromatin H3K9me2 (Luijsterburg et al., 2009). We also found that while CSD HP1 $\beta$ became enriched, the HP1 $1 \beta$ methyl-binding CD domain was not enriched at DSB sites in transcribed regions, another indication $\mathrm{HP} 1 \beta$ recruitment is $\mathrm{H} 3 \mathrm{~K} 9$ methylation independent (Fig. 2C, D). To determine whether any known CSD interacting proteins impacted HP1 $\beta$ recruitment, we performed co-immunoprecipitation studies and confirmed that both KAP1 and CAF1 interact with HP1 (Bartova et al., 2017; Brasher et al., 2000; Lemaitre and Soutoglou, 2014; Lorkovic et al., 2017; Nakatani et al., 2006; White et al., 2012), more specifically the CSD (Fig. 2E, Supplementary Fig. 2C).

CAF1 is involved in histone assembly, we next determined whether CAF1 depletion altered HP1 $\beta$ recruitment at DNA damage sites. ChIP-based recruitment analysis indicated that CAF1 depletion decreased both HP1 $1 \beta$ and CSD HP1 recruitment to DSBs (Fig. 2F). Moreover, CSD HP1 $\beta$ expression after CAF1/HP1 
co-depletion no longer rescued the IR sensitive phenotype of HP1 $\beta$ depleted cells

(Fig. 2G). In addition, DNA DSB repair by HR was no longer rescued in HP1ß depleted cells by CSD HP1 $\beta$ expression in CAF1 co-depleted cells (Fig. 2 H). In contrast, CSD HP1 did restore HR in KAP1/HP1 $\beta$ co-depleted cells (Supplementary Fig. 2D), suggesting HP1 $\beta$ CSD interaction with CAF1, but not KAP1, is critical for effective HR repair.

\section{The HP1 $\beta$ CSD and DNA end resection}

Depletion of HP1 $\beta$ has been reported to decrease BRCA1 foci formation (Alagoz et al., 2015; Fukuda et al., 2016; Lee et al., 2013), which is essential for DNA resection; however, details of the underlying mechanism are unclear. During DNA damage repair, displacement of 53BP1 at DSBs requires BRCA1 and occurs prior to recruitment of proteins involved in resection (Feng et al., 2013; Mattoo et al., 2017). To identify a possible role for HP1 $\beta$ in resection, we measured single strand DNA production at a DSB site in control and HP1 $\beta$ depleted cells using the ERAsiSl assay system (Zhou et al., 2014) (Fig. 3A, Supplementary Fig. 3A). Time course studies in control cells of the tamoxifen induced ER-AsiSI DNA cleavage site indicated single stranded DNA (ssDNA) levels started to peak from $2 \mathrm{hr}$ and maximum ssDNA formation occurred at $4 \mathrm{hr}$ with a slight decline by $6 \mathrm{hr}$ (Fig. 3A). As expected, measured resection at the distal site 1618 bp from the DSB was proportionately slightly less than at the proximal 335 bp site. In contrast, after HP1 depletion, ssDNA formation was substantially less and only slowly increased 
before reaching a maxima at $6 \mathrm{hr}$ with significantly decreased formation $335 \mathrm{bp}$ or 1618 bp from the DSB site (Fig. 3A).

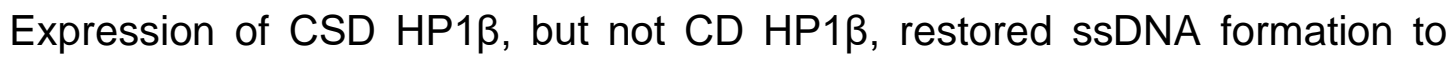
levels in non-HP1 $\beta$ depleted cells (Fig. 3B). Since CAF1 interacts with HP1 (Fig. 2E), we further examined whether depletion of CAF1 also affected resection and found CAF1 depletion blocked the ability of CSD expression to restore resection in HP1 $1 \beta$ depleted cells (Fig. 3C, D). Consistent with these results, foci formation by the DNA single strand binding protein RAD51 was reduced in HP1 $1 \beta$ depleted cells and restored by HP1 $\beta$ or CSD HP1 expression (Fig. 3E, Supplementary Fig. 3B). These results indicate that HP1 is required at an early step in HRmediated DNA repair (Fig. 3A-C) that is functionally dependent on the HP1 $\beta$ CSD.

Furthermore, we observed that 53BP1 depletion increased single strand DNA (ssDNA) and RAD51 foci formation but concurrent HP1 $\beta$ depletion restored normal levels of ssDNA and RAD51 foci formation (Fig. 3E-G). CtIP depletion, as expected, decreased ssDNA and RAD51 foci formation, and this was not further decreased by simultaneous HP1 $\beta$ depletion (Fig. 3E, F), suggesting that CtIP and HP1 $\beta$ function in the same pathway for resection. These results correlated with DSB repair by HR (Fig. 3F, G, Supplementary Fig. 3C) in that HP1 $\beta$ or CtIP depletion reduced HR-mediated DSB repair.

\section{CSD HP1 $\beta$ is critical for 53BP1 displacement and BRCA1 foci formation}

HP1 $\beta$ depletion reduced the frequency of IR-induced BRCA1 foci formation. Since 53BP1 and RIF1 block IR-induced BRCA1 foci formation (Bunting et al., 2010; 
Escribano-Diaz et al., 2013), we expressed wild type or HP1 $\beta$ mutants in HP1 $\beta$ depleted cells and measured co-localization of 53BP1 and RIF1 foci after irradiation (Supplementary Fig. 3D). Neither HP1 $\beta$ depletion nor expression of CD HP1 $\beta$ or CSD HP1 $\beta$ in depleted cells affected IR-induced 53BP1/RIF1 colocalization (Supplementary Fig. 3D). However, HP1 $\beta$ depletion reduced the frequency of BRCA1 foci formation (Fig. 4A, B). To determine which domain of HP1 $\beta$ is required for BRCA1 recruitment at DNA damage, we depleted endogenous HP1 $\beta$ and expressed wild type, CD or CSD domain. We found that wild-type and CSD HP1 $\beta$ expression, but not CD HP1 $\beta$,rescued BRCA1 foci formation (Fig. 4A, B). HP1 $\beta$ depleted cells had reduced co-localization of 53BP1/BRCA1 foci, whereas CSD HP1 $\beta$ expression rescued co-localization of 53BP1/BRCA1, but not CD expression (Fig. 4A-C).

To directly measure BRCA1 recruitment at DSBs, we used two different I-Sce1 inducible DSB sites cell lines (Chr1A, Chr1B) as described previously (Supplementary Fig. 2) (Horikoshi et al., 2019). Chromatin immuno-precipitation (ChIP) studies detected a significant increase in BRCA1 at the Chr1A site (generich) after DSB induction and an insignificant BRCA1 increase at the Chr1B site (gene-poor) (Fig. 4D). Depletion of HP1 $\beta$ significantly diminished BRCA1 recruitment at the Chr1A DSB site (Fig. 4D-F). The ability of the HP1 $\beta$ deletion mutants to restore BRCA1 recruitment to DSBs differed dramatically, as CD HP1 $\beta$ expression did not restore BRCA1 recruitment in HP1 $\beta$ depleted cells (Fig. 4E), whereas CSD HP1 $\beta$ restored BRCA1 recruitment (Fig. 4F).

The influence of HP1 $\beta$ on cell survival after irradiation is ATM independent 
To determine whether the HP1 $\beta$ repair function is ATM dependent, HP1 $\beta$ depleted cells were treated with an ATM inhibitor (KU55993) and cell survival measured after IR (Fig. 5A). Either HP1 $\beta$ depletion or ATM inhibition increased cell sensitivity to IR (Fig. 1B, 5A). The combined treatments produced a further, synergistic decrease in cell survival (Fig. 5A), suggesting that HP1 $\beta$ and ATM effect survival by separate pathways. This was further confirmed by depletion of HP1 $\beta$ in ATM null cells (GM5823+hTERT) (Wood et al., 2001) where depletion of HP1 $\beta$ (Supplementary Fig. 4A) further decreased cell survival post irradiation (Supplementary Fig. 4B). Depletion of HP1 $\beta$ had no effect on IR-induced ATM auto-phosphorylation (Supplementary Fig. 4B,C) and phosphorylated p-MDC1 foci formation (Fig. 5B, Supplementary Fig. 4D), suggesting HP1 $\beta$ functions independently of the ATM-mediated pathway in the IR-induced DNA damage response.

\section{HP1 $\beta$ interacts with RING1A to facilitate BRCA1 foci formation}

Mono-ubiquitinated $\mathrm{H} 2 \mathrm{~A}$ at lysine 119 is essential for BRCA1 recruitment to DSBs (Hung et al., 2017). We therefore tested for interactions between HP1 $\beta$ and Polycomb repressive complex 1 (PRC1), which contains an E3 ubiquitin ligase, by co-immunoprecipitation. We found that HP1 $\beta$ interacts with the PRC1 complex protein RING1A (Fig. 5C,D). Deletion analysis indicated HP1 $\beta$ interacted with RING1A specifically through CSD but not CD (Fig. 5D).

HP1 $1 /$ RING1A interaction increases substantially in cells 30 mins after irradiation (Supplementary Fig. 5A). RING1A was enriched after DSB induction 
at the gene-rich region (Chr1A), while less enrichment was observed at the gene poor DSB site (Fig. 5E). This interaction was confirmed by in vitro studies using recombinantly purified RING1A-FL and CSD HP1 $\beta$ where CSD HP1 $\beta$ pulls down RING1A-FL (Supplementary Fig. 5B).

Additional insights into the HP1 $\beta$ and RING1A interaction were obtained from protein docking models. Full-length HP1 $\beta$ and RING1A were modelled using TrRosetta (Yang et al., 2020) before running the rigid-body protein-protein docking using ClusPro docking server (Kozakov et al., 2017). The selection criteria of topranked model were based on the known protein-protein interactions on RING1A, where its $\mathrm{N}$-terminal domain interacts with polycomb complex protein Bmi1 (McGinty et al., 2014), and on HP1 $\beta$, where the CSD tends to form a dimer via its $\alpha$-helix (Ekblad et al., 2005; Kumar and Kono, 2020). For example, the I161E mutant on the CSD $\alpha$-helix was reported to disrupt protein-protein interaction (Brasher et al., 2000). The docking model revealed that the same $\alpha$-helix of CSD may interact with RING1A (Supplementary Fig. 5C). Although CSD HP1 $\beta$ and CD HP1 $\beta$ share a similar fold, their sequence identity is only $\sim 23 \%$. Sequence conservation and secondary structure analyses show the CSD a-helix is mostly conserved, while CD a-helix is not (Supplementary Fig. 5D, E). Moreover, CD HP1 $\beta$ could not bind to RING1A via the same CSD binding site as its predicted long a-helix would seriously clash with the RING1A structure (Supplementary Fig. 5E). Interestingly, the RING1A $\alpha$-helix binding site is also highly conserved, suggesting important functional roles of these residues. In sum, our structurebased docking model predicts the potential RING1A binding site can only interact 
with the HP1 $\beta$ CSD, not the CD, consistent with our cellular results (Fig.5D, Supplementary Fig.5).

To determine whether RING1A promotes BRCA1 recruitment to DSBs, we examined BRCA1 enrichment at the Chr1A and Chr1C sites after DSB induction in cells depleted of either HP1 $1 \beta$ or RING1A or in combination. We found under all conditions significantly reduced BRCA1 recruitment (Fig. 5G). Similarly, RING1A depletion reduced IR-induced BRCA1 foci formation (Fig. $5 \mathrm{H}$ ), and reduced single ssDNA formation 335bp and $1618 \mathrm{bp}$ distal from the DSB (Fig. 3A, 5F). These foci and SsDNA reductions resemble those from HP1 $\beta$ depletion, while depletion of both produced no additional decrease (Fig. 5F). This indicates HP1 $\beta$ and RING1A function epistatically for resection during DSB repair by HR.

\section{HP1 $\beta$ promotes ubiquitination of H2A by RING1A}

$\mathrm{HP} 1 \beta$ is required for BRCA1 distribution at DSBs (Fig. 4), and the PRC1 complex protein RING1A ubiquitinates H2A at lysine 119 (Benitz et al., 2016; Patel et al., 2017; Rossi et al., 2016). We reasoned, that HP1 $\beta$ might be essential for H2A ubiquitination and subsequent BRCA1 recruitment to DSBs. A significant IRinduced increase in cellular $\mathrm{H} 2 \mathrm{~A}$ poly-ubiquitination was observed that was largely lost in HP1 $\beta$ depleted cells (Fig. 6A, B). Furthermore ubiquitinated (ub)-H2AK119 enrichment was observed at the Chr1A site after DSB induction, whereas HP1 $\beta$ depletion significantly reduced ub-H2AK119 enrichment at the site (Fig. 6C).

These results were complemented by examining the effect of expressing a carboxy-end H2A ubiquitinated protein (Zhu et al., 2011) in HP1ß depleted cells. 
Expression of the conjugated $\mathrm{uH} 2 \mathrm{~A}$ protein rescued IR-induced cell killing and improved HR mediated repair in HP1 $\beta$ depleted cells (Fig. 6D, E). Expression of ub-H2AK119 rescued cells from enhanced IR-induced cell death whether in the presence or absence of ATM inhibitor, suggesting ub-H2AK119, as does HP1 $\beta$, functions at DSBs independently of ATM function (Fig. 6D). Overall, these results identify an interaction between HP1 $\beta$ and PRC1 complex protein (RING1A) that facilitates $\mathrm{H} 2 \mathrm{~A}$ ubiquitination and thus BRCA1 recruitment at DSBs (Fig. 6E).

\section{Discussion:}

Conflicting studies have suggested that HP1 $\beta$ facilitates DNA repair, or is inhibitory to DNA repair (Ayoub et al., 2008; Ayoub et al., 2009; Dinant and Luijsterburg, 2009; Horikoshi et al., 2019). Loss of function HP1 $\beta$ studies in Caenorhabditis elegans, yeast and human indicated increased sensitivity to IR, suggesting that HP1 $\beta$ contributes to DNA damage repair by HR (Ahringer and Gasser, 2018; Jang et al., 2018; Wei et al., 2018). Chromatin associated remodeling factors are different in gene rich vs. gene poor regions and can influence the recruitment of different DNA repair factors or proteins at DSB sites (Horikoshi et al., 2019). Interestingly HP1 $\beta$ is more efficiently recruited and promotes HR at DSBs located in gene-rich regions as compared gene-poor regions. Some studies suggest that after DNA damage, HP1 $\beta$ is recruited to DSB sites and then enrichment is extended beyond the break site (Ayrapetov et al., 2014; Goodarzi and Jeggo, 
2013; Hunt et al., 2013). However, there are also contradictory results regarding accumulation of HP1 $\beta$ at DSB sites (Ayoub et al., 2009; Ball and Yokomori, 2009; Luijsterburg et al., 2009; Zeng et al., 2010). Adding to the existing literature and to defining the mechanism for HP1 $\beta$ function, we report that HP1 $1 \beta$ recruitment to DSBs in transcriptionally active regions can be mediated independently by either the HP1 $\beta$ CD or CSD domain; however, CSD HP1 $\beta$ recruitment levels at DSB sites are significantly higher. Further, we explored factors essential for CSD HP1 $\beta$ recruitment at DSB sites and found that CAF1 is required and depletion of CAF1 increased sensitivity to IR (Huang et al., 2018). Reducing CAF1 in HP1 $\beta$ depleted cell blocked the ability of CSD HP1 $\beta$ to rescue the IR sensitivity, indicating CAF1 and CSD HP1 $\beta$ act in the same HR pathway. Consistent with the HP1 $\beta$ role in HR, HP1 $\beta$ depletion reduced BRCA1 foci formation in irradiated cells (Lee and Ann, 2015; Lee et al., 2013; Lee et al., 2015). Earlier studies have shown that BRCA1 plays a role in 5' - 3' DNA end resection which generates the ssDNA substrate that is subsequently loaded with RAD51. Importantly, regulation of resection can control DSB repair mechanism, pathway selection, and biological outcomes to DSBs (Dutta et al., 2017; Shibata et al., 2014). Here we report on the mechanism by which BRCA1 recruitment to chromatin DSBs is influenced by HP1 $\beta$. We found that CSD HP1 $\beta$ recruits BRCA1 to DSB sites at gene-rich sites. Furthermore, this is independent of ATM as the depletion of HP1 $\beta$ and ATM inhibition increased cell kill synergistically which supports and extends previous results (Alagoz et al., 2015), suggesting that BRCA1 recruitment through CSD HP1 $\beta$ is independent of the ATM function. 
Histone ubiquitination modifications (K13-15, K118-119, K127-129) and E3 ubiquitin ligases (RNF8, RING1B, RNF168, BARD1) play critical roles in recruitment of 53BP1 and BRCA1 (Chapman et al., 2012; Daley and Sung, 2014; Munoz et al., 2014). PRC1 complex proteins interact with DNA repair proteins and this affinity is increased after DNA damage (Chandler et al., 2014). In mammalian systems, the PRC1 complexes are heterogeneous with six different PRC1 complexes known (PRC 1.1 to PRC 1.6); however, all these complexes purify together with RING1A/B (Gao et al., 2012). In transcriptionally repressed regions, PRC1 complex proteins ubiquitinate $\mathrm{H} 2 \mathrm{~A}$ at lysine $118 / 119$, which is required for any subsequent BRCA1 recruitment (Ginjala et al., 2011; Zhu et al., 2011). Direct binding of CSD HP1 $\beta$ with RING1A evidently creates an efficient $\mathrm{H} 2 \mathrm{~A}$ ubiquitination complex at DSBs in actively transcribing regions since we found that depletion of either HP1 $\beta$ or RING1A reduced H2A K118-119 ubiquitination levels. Moreover, HP1 $\beta$ and RING1A likely act as a complex in BRCA1 recruitment as our results showed no significant difference in H2A-ub118 -119 reduction between depleting HP1 $\beta$ and RING1A separately or together. These collective results unveil how HP1 $\beta$ is recruited to DSBs in gene-rich regions and how HP1 $\beta$ subsequently promotes BRCA1 recruitment to further DNA damage repair during HR by stimulating resection (Fig. 7). 


\section{Materials and methods}

Human cell lines H1299 and U2OS were obtained from ATCC (Manassas, VA) and cultured in DMEM + $10 \%$ FBS media. Cell transfection with siRNA or plasmid was as described previously(Ahmed et al., 2018; Chakraborty et al., 2018; Mujoo et al., 2017). Resection assay reagents (ER-AsiSI plasmids and U2OS cells) were a generous gift from T. Paull (University of Texas Austin, TX). The pCDNA3.1 FlagHP1 $\beta$, and mutant DNAs (PCDNA 3.1 CD HP1 $\beta$ and CSD HP1 $\beta$ were transfected into $\mathrm{H} 1299$ cells or U2OS cells.

\section{Antibodies}

The list of primary antibodies used for immuno blot (IB or immunofluorescence (IF) analysis are Rat anti-HP1ß (IB 1:500,ab10811), mouse anti-HP1Y (IB, 1:1,000;ab217999); mouse anti-HP1 $\alpha$ (IB, 1:1,000, ab77256); mouse anti-yH2AX (IB 1:1000, IF: 500, 05-636; Millipore, Mouse anti-human RAD51 (IF, 1:500, ab133534); Rabbit anti RING1A (IB: 1:250, ab32644), Rabbit anti RING2 (IB 1: 500, ab101273) Rabbit anti CtIP (IB: 1:1000, ab70163), Rabbit anti CAF1 (IB: 1000, ab126625), Rabbit anti KAP1 (IB1: 500, ab10484), Rabbit anti 53BP1(IB: 1:500, IF: 1:250, SC-22760) Mouse anti FLAG (IB 1:500), Rabbit anti HA ( IB 1:250). Secondary antibodies used were: for IB, HRP-conjugated affinity-purified sheep anti-mouse or donkey anti-rabbit (1:5000; Jackson Immuno Research Laboratories, Inc.); and for IF, goat anti-mouse or anti-rabbit coupled to Alexa Fluor 488 or 594 (1:1,000; Invitrogen).

\section{Immunofluorescence}


H1299 cells were transfected with control siRNA or 3' UTR HP1 siRNA to deplete endogenous HP1 1 . HP1 siRNA treated cells were transfected with Flag HP1, Flag CD HP1 $1 \beta$, or Flag CSD HP1 $\beta$. The cells were irradiated and samples obtained at increasing times after irradiation. After fixing with $4 \%$ paraformaldehyde or methanol, cells were immuno-stained with different antibodies as mentioned in text (Chakraborty et al., 2018; Gupta et al., 2014b; Horikoshi et al., 2016; Mattoo et al., 2017; Singh et al., 2018). Images captured by using a Zeiss Axio Imager and analyzed by using Image J software.

\section{ssDNA Quantification assay by using the ER-AsiSI system}

A quantitative ssDNA resection product was measured as previously described (Chakraborty et al., 2018; Singh et al., 2018; Zhou et al., 2014). Exponentially growing ER-AsiSI U2OS cells treated with tamoxifen $(300 \mathrm{ng} / \mathrm{ml})$ for $3 \mathrm{hr}$, and 6 million treated cells were embedded in $0.6 \%$ low melting agarose. A 50 ul agarose ball of cells was serially treated with $1 \mathrm{ml}$ of EDTA Sarcosine proteinase K (ESP) buffer $(0.5 \mathrm{M}$ EDTA, $2 \% \mathrm{~N}$-lauroylsarcosine, $1 \mathrm{mg} / \mathrm{ml}$ of proteinase $\mathrm{K}$, and $1 \mathrm{mM}$ $\left.\mathrm{CaCl}_{2}[\mathrm{pH} 8.0]\right)$ and $\mathrm{HS}$ buffer ((1.85 M NaCl, 0.15 M KCl, $5 \mathrm{mM} \mathrm{MgCl}$, 2 mM 213 EDTA, $4 \mathrm{mM}$ MTris, and $0.5 \%$ Triton X-100 [pH 7.5] for 20h. Afterwards the cells were washed six times with phosphate buffer (8 $\mathrm{mM} \mathrm{Na}_{2} \mathrm{HPO}_{4}, 1.5 \mathrm{mM} \mathrm{KH}_{2} \mathrm{PO}_{4}$, $133 \mathrm{mM} \mathrm{KCl}$, and $\left.0.8 \mathrm{mM} \mathrm{MgCl}_{2}[\mathrm{pH} 7.4]\right)$. These agarose balls are melted at $70^{\circ} \mathrm{C}$ for 10 mins, diluted 15 fold with distilled $\mathrm{H} 20$ then digested with BsrG1 restriction enzymes. A 3ul aliquot of mock or digested sample was used for ssDNA analysis by quantitative PCR. 


\section{H2A Ubiquitination assays}

H1299 cells were co-transfected with control siRNA, HP1ßsiRNA or Flag H2A plasmid. Exponentially growing cells were irradiated (10 Gy) and samples harvested at different time after irradiation. $\mathrm{H} 2 \mathrm{~A}$ ubiquitination was analyzed with anti-Flag antibody (Sigma) (Ahmed et al., 2018; Singh et al., 2018).

\section{Cloning and protein purification}

Human FL-RING1A (1-406aa) and CSD HP1ß(80-185aa) were subcloned into bacterial expression 1GFP vector (Addgene \#29663) and 1B vector (Addgene \#29653), respectively and proteins were purified as previously described (Hambarde et al., 2021) with changes in buffers. Briefly, RING1A was purified from HisTrap column, TEV-cleavage to remove His-GFP tags, and Superdex 75 column in the final buffer (25 mM HEPES, pH 7.6, $150 \mathrm{mM} \mathrm{NaCl}, 100 \mu \mathrm{M} \mathrm{ZnCl}_{2}, 5 \%$

glycerol, 5 mM BME); CSD HP1 $\beta$ was purified from HisTrap column and Superdex 75 column in the final buffer ( $25 \mathrm{mM}$ HEPES, $\mathrm{pH} 7.5,150 \mathrm{mM} \mathrm{NaCl}, 2 \%$ glycerol, 1 mM DTT, 1 mM BME).

\section{Invitro pull down assay}

FL-RING1A was incubated with His6-CSD HP1 $\beta$ in molar ratio $1: 2$ in buffer $\mathrm{H}(20$ mM Tris, $\mathrm{pH}$ 8, $70 \mathrm{mM} \mathrm{NaCl}$, 5\% glycerol, $5 \mathrm{mM} \mathrm{BME,} 100 \mu \mathrm{M} \mathrm{ZnCl} 2$ ) on ice for 20 min. The mixture was loaded onto Ni-NTA resin, which was pre-equilibrated with Buffer $\mathrm{H}$ and wash with buffer $\mathrm{H}$ excessively, followed by elution with Buffer $\mathrm{H}$ plus 
$300 \mathrm{mM}$ imidazole. The fractions were analyzed by SDS-PAGE and western blot using anti-RING1A (GTX50803 from GeneTex) and anti-HP1ß (sc-20699 from Santa Cruz Biotechnology) antibodies.

\section{Structure prediction and modelling}

Full length RING1A and HP1 $\beta$ models were predicted by a deep learning-based method, TrRosetta (Yang et al., 2020), using webserver (https://robetta.bakerlab.org). The predicted models were evaluated by error estimate and the known crystal structure homologs [Ring1B (PDB: 4R8P, chain L); HP1 $\beta$ (PDB: 3F2U for CD; PDB: 5T1G for CSD)]. The best models were docked together by ClusPro protein docking webserver (https://cluspro.bu.edu) (Kozakov et al., 2017), and the top 10 ranked docking models were evaluated by known crystal structure homolog (PDB: 4R8P). RRING1B-Bmi1 interactions. Final docking model was generated by using Chimera and structural conservation was performed using ConSurf webserver (https://consurf.tau.ac.il) (Ashkenazy et al., 2016; Landau et al., 2005; Pettersen et al., 2004) by inputting the TrRosetta models of RING1A and HP1 $\beta$. 


\section{Acknowledgements:}

We acknowledges NIH grants supported by NIH R01 CA129537 and R01 GM109768 and The Houston Methodist Research Institute. Special thanks are due to Nobuo Horikoshi for generating cell lines. Work by JAT and CLT was supported by P01 CA092584, R35 CA220430, Cancer Prevention Research Institute of Texas (CPRIT) grant RP180813, and a Robert A. Welch Chemistry Chair. We thank Walter N Hittelman and Nitika Taneja for their suggestions.

\section{AUTHOR CONTRIBUTIONS}

V.C., C.R.H., and T.K.P. directed the study. V.C., C.R.H., R.P., C.L.T., S.C. and T.K.P. contributed to the design. V.C., R.K.P., C.R.H., S.C. and T.K.P. performed the experiments. J.A.T. X.W. and C.L.T did in-vitro experiments, structure analysis, prediction, and modeling. V.C., C.R.H., K.T, . C.L.T., J.A.T. and T.K.P wrote the paper.

DECLARATION OF INTERESTS: The authors declare no competing interests. 


\section{Bibliography:}

Ahmed, K.M., Pandita, R.K., Singh, D.K., Hunt, C.R., and Pandita, T.K. (2018). beta1-Integrin Impacts Rad51 Stability and DNA Double-Strand Break Repair by Homologous Recombination. Mol Cell Biol 38.

Ahringer, J., and Gasser, S.M. (2018). Repressive Chromatin in Caenorhabditis elegans: Establishment, Composition, and Function. Genetics 208, 491-511.

Alagoz, M., Katsuki, Y., Ogiwara, H., Ogi, T., Shibata, A., Kakarougkas, A., and Jeggo, P. (2015). SETDB1, HP1 and SUV39 promote repositioning of 53BP1 to extend resection during homologous recombination in $\mathrm{G} 2$ cells. Nucleic Acids Res 43, 7931-7944.

Ashkenazy, H., Abadi, S., Martz, E., Chay, O., Mayrose, I., Pupko, T., and BenTal, N. (2016). ConSurf 2016: an improved methodology to estimate and visualize evolutionary conservation in macromolecules. Nucleic Acids Res 44, W344-350. Aucott, R., Bullwinkel, J., Yu, Y., Shi, W., Billur, M., Brown, J.P., Menzel, U., Kioussis, D., Wang, G., Reisert, I., et al. (2008). HP1-beta is required for development of the cerebral neocortex and neuromuscular junctions. J Cell Biol 183, 597-606.

Ayoub, N., Jeyasekharan, A.D., Bernal, J.A., and Venkitaraman, A.R. (2008). HP1beta mobilization promotes chromatin changes that initiate the DNA damage response. Nature 453, 682-686.

Ayoub, N., Jeyasekharan, A.D., and Venkitaraman, A.R. (2009). Mobilization and recruitment of HP1: a bimodal response to DNA breakage. Cell Cycle 8, 29452950.

Ayrapetov, M.K., Gursoy-Yuzugullu, O., Xu, C., Xu, Y., and Price, B.D. (2014). DNA double-strand breaks promote methylation of histone $\mathrm{H} 3$ on lysine 9 and transient formation of repressive chromatin. Proc Natl Acad Sci U S A 111, 91699174.

Ball, A.R., Jr., and Yokomori, K. (2009). Revisiting the role of heterochromatin protein 1 in DNA repair. J Cell Biol 185, 573-575.

Bartova, E., Malyskova, B., Komurkova, D., Legartova, S., Suchankova, J., Krejci, J., and Kozubek, S. (2017). Function of heterochromatin protein 1 during DNA repair. Protoplasma 254, 1233-1240.

Benitz, S., Regel, I., Reinhard, T., Popp, A., Schaffer, I., Raulefs, S., Kong, B., Esposito, I., Michalski, C.W., and Kleeff, J. (2016). Polycomb repressor complex 1 promotes gene silencing through H2AK119 mono-ubiquitination in acinar-to-ductal metaplasia and pancreatic cancer cells. Oncotarget 7, 11424-11433.

Bennett, G., Papamichos-Chronakis, M., and Peterson, C.L. (2013). DNA repair choice defines a common pathway for recruitment of chromatin regulators. Nat Commun 4, 2084.

Brasher, S.V., Smith, B.O., Fogh, R.H., Nietlispach, D., Thiru, A., Nielsen, P.R., Broadhurst, R.W., Ball, L.J., Murzina, N.V., and Laue, E.D. (2000). The structure of mouse HP1 suggests a unique mode of single peptide recognition by the shadow chromo domain dimer. EMBO J 19, 1587-1597.

Bunting, S.F., Callen, E., Wong, N., Chen, H.T., Polato, F., Gunn, A., Bothmer, A., Feldhahn, N., Fernandez-Capetillo, O., Cao, L., et al. (2010). 53BP1 inhibits 
homologous recombination in Brca1-deficient cells by blocking resection of DNA breaks. Cell 141, 243-254.

Chakraborty, S., Pandita, R.K., Hambarde, S., Mattoo, A.R., Charaka, V., Ahmed, K.M., lyer, S.P., Hunt, C.R., and Pandita, T.K. (2018). SMARCAD1 Phosphorylation and Ubiquitination Are Required for Resection during DNA Double-Strand Break Repair. iScience 2, 123-135.

Chandler, H., Patel, H., Palermo, R., Brookes, S., Matthews, N., and Peters, G. (2014). Role of polycomb group proteins in the DNA damage response--a reassessment. PLoS One 9, e102968.

Chapman, J.R., Sossick, A.J., Boulton, S.J., and Jackson, S.P. (2012). BRCA1associated exclusion of 53BP1 from DNA damage sites underlies temporal control of DNA repair. J Cell Sci 125, 3529-3534.

Chaturvedi, P., Khanna, R., and Parnaik, V.K. (2012). Ubiquitin ligase RNF123 mediates degradation of heterochromatin protein 1alpha and beta in lamin A/C knock-down cells. PLoS One 7, e47558.

Daley, J.M., and Sung, P. (2014). 53BP1, BRCA1, and the choice between recombination and end joining at DNA double-strand breaks. Mol Cell Biol 34, 1380-1388.

Dinant, C., and Luijsterburg, M.S. (2009). The emerging role of HP1 in the DNA damage response. Mol Cell Biol 29, 6335-6340.

Dutta, A., Eckelmann, B., Adhikari, S., Ahmed, K.M., Sengupta, S., Pandey, A., Hegde, P.M., Tsai, M.S., Tainer, J.A., Weinfeld, M., et al. (2017). Microhomologymediated end joining is activated in irradiated human cells due to phosphorylationdependent formation of the XRCC1 repair complex. Nucleic Acids Res 45, 25852599.

Ekblad, C.M., Chavali, G.B., Basu, B.P., Freund, S.M., Veprintsev, D., HughesDavies, L., Kouzarides, T., Doherty, A.J., and Itzhaki, L.S. (2005). Binding of EMSY to HP1beta: implications for recruitment of HP1 beta and BS69. EMBO Rep 6, 675680.

Escribano-Diaz, C., Orthwein, A., Fradet-Turcotte, A., Xing, M., Young, J.T., Tkac, J., Cook, M.A., Rosebrock, A.P., Munro, M., Canny, M.D., et al. (2013). A cell cycle-dependent regulatory circuit composed of 53BP1-RIF1 and BRCA1-CtIP controls DNA repair pathway choice. Mol Cell 49, 872-883.

Feng, L., Fong, K.W., Wang, J., Wang, W., and Chen, J. (2013). RIF1 counteracts BRCA1-mediated end resection during DNA repair. J Biol Chem 288, 1113511143.

Finn, E.H., and Misteli, T. (2019). Molecular basis and biological function of variability in spatial genome organization. Science 365.

Fnu, S., Williamson, E.A., De Haro, L.P., Brenneman, M., Wray, J., Shaheen, M., Radhakrishnan, K., Lee, S.H., Nickoloff, J.A., and Hromas, R. (2011). Methylation of histone $\mathrm{H} 3$ lysine 36 enhances DNA repair by nonhomologous end-joining. Proc Natl Acad Sci U S A 108, 540-545.

Fukuda, T., Tsuruga, T., Kuroda, T., Takeuchi, J., Wu, W., and Ohta, T. (2016). The BARD1/HP1 interaction: Another clue to heterochromatin involvement in homologous recombination. Mol Cell Oncol 3, e1030535. 
Gao, Z., Zhang, J., Bonasio, R., Strino, F., Sawai, A., Parisi, F., Kluger, Y., and Reinberg, D. (2012). PCGF homologs, CBX proteins, and RYBP define functionally distinct PRC1 family complexes. Mol Cell 45, 344-356.

Georgoulis, A., Vorgias, C.E., Chrousos, G.P., and Rogakou, E.P. (2017). Genome Instability and gammaH2AX. Int J Mol Sci 18.

Ginjala, V., Nacerddine, K., Kulkarni, A., Oza, J., Hill, S.J., Yao, M., Citterio, E., van Lohuizen, M., and Ganesan, S. (2011). BMI1 is recruited to DNA breaks and contributes to DNA damage-induced $\mathrm{H} 2 \mathrm{~A}$ ubiquitination and repair. Mol Cell Biol 31, 1972-1982.

Goodarzi, A.A., and Jeggo, P.A. (2013). The repair and signaling responses to DNA double-strand breaks. Adv Genet 82, 1-45.

Guo, X., Bai, Y., Zhao, M., Zhou, M., Shen, Q., Yun, C.H., Zhang, H., Zhu, W.G., and Wang, J. (2018). Acetylation of 53BP1 dictates the DNA double strand break repair pathway. Nucleic Acids Res 46, 689-703.

Gupta, A., Hunt, C.R., Hegde, M.L., Chakraborty, S., Chakraborty, S., Udayakumar, D., Horikoshi, N., Singh, M., Ramnarain, D.B., Hittelman, W.N., et al. (2014a). MOF phosphorylation by ATM regulates 53BP1-mediated doublestrand break repair pathway choice. Cell Rep 8, 177-189.

Gupta, A., Hunt, C.R., Hegde, M.L., Chakraborty, S., Udayakumar, D., Horikoshi, N., Singh, M., Ramnarain, D.B., Hittelman, W.N., Namjoshi, S., et al. (2014b). MOF phosphorylation by ATM regulates 53BP1-mediated double-strand break repair pathway choice. Cell Rep 8, 177-189.

Hambarde, S., Tsai, C.L., Pandita, R.K., Bacolla, A., Maitra, A., Charaka, V., Hunt, C.R., Kumar, R., Limbo, O., Le Meur, R., et al. (2021). EXO5-DNA structure and BLM interactions direct DNA resection critical for ATR-dependent replication restart. Mol Cell 81, 2989-3006 e2989.

Horikoshi, N., Pandita, R.K., Mujoo, K., Hambarde, S., Sharma, D., Mattoo, A.R., Chakraborty, S., Charaka, V., Hunt, C.R., and Pandita, T.K. (2016). beta2-spectrin depletion impairs DNA damage repair. Oncotarget 7, 33557-33570.

Horikoshi, N., Sharma, D., Leonard, F., Pandita, R.K., Charaka, V.K., Hambarde, S., Horikoshi, N.T., Gaur Khaitan, P., Chakraborty, S., Cote, J., et al. (2019). Preexisting H4K16ac levels in euchromatin drive DNA repair by homologous recombination in S-phase. Commun Biol 2, 253.

Huang, T.H., Fowler, F., Chen, C.C., Shen, Z.J., Sleckman, B., and Tyler, J.K. (2018). The Histone Chaperones ASF1 and CAF-1 Promote MMS22L-TONSLMediated Rad51 Loading onto ssDNA during Homologous Recombination in Human Cells. Mol Cell 69, 879-892 e875.

Hung, S.H., Wong, R.P., Ulrich, H.D., and Kao, C.F. (2017). Monoubiquitylation of histone $\mathrm{H} 2 \mathrm{~B}$ contributes to the bypass of DNA damage during and after DNA replication. Proc Natl Acad Sci U S A 114, E2205-E2214.

Hunt, C.R., Ramnarain, D., Horikoshi, N., lyengar, P., Pandita, R.K., Shay, J.W., and Pandita, T.K. (2013). Histone modifications and DNA double-strand break repair after exposure to ionizing radiations. Radiat Res 179, 383-392.

Jang, S.M., Kauzlaric, A., Quivy, J.P., Pontis, J., Rauwel, B., Coluccio, A., Offner, S., Duc, J., Turelli, P., Almouzni, G., et al. (2018). KAP1 facilitates reinstatement of heterochromatin after DNA replication. Nucleic Acids Res 46, 8788-8802. 
Kaidi, A., Weinert, B.T., Choudhary, C., and Jackson, S.P. (2010). Human SIRT6 promotes DNA end resection through CtIP deacetylation. Science 329, 1348-1353. Kakarougkas, A., Ismail, A., Klement, K., Goodarzi, A.A., Conrad, S., Freire, R., Shibata, A., Lobrich, M., and Jeggo, P.A. (2013). Opposing roles for 53BP1 during homologous recombination. Nucleic Acids Res 41, 9719-9731.

Kozakov, D., Hall, D.R., Xia, B., Porter, K.A., Padhorny, D., Yueh, C., Beglov, D., and Vajda, S. (2017). The ClusPro web server for protein-protein docking. Nat Protoc 12, 255-278.

Kumar, A., and Kono, H. (2020). Heterochromatin protein 1 (HP1): interactions with itself and chromatin components. Biophys Rev 12, 387-400.

Kumar, R., Horikoshi, N., Singh, M., Gupta, A., Misra, H.S., Albuquerque, K., Hunt, C.R., and Pandita, T.K. (2012). Chromatin modifications and the DNA damage response to ionizing radiation. Frontiers in oncology 2, 214.

Landau, M., Mayrose, I., Rosenberg, Y., Glaser, F., Martz, E., Pupko, T., and BenTal, N. (2005). ConSurf 2005: the projection of evolutionary conservation scores of residues on protein structures. Nucleic Acids Res 33, W299-302.

Lee, Y.H., and Ann, D.K. (2015). Bi-phasic expression of Heterochromatin Protein 1 (HP1) during breast cancer progression: Potential roles of HP1 and chromatin structure in tumorigenesis. J Nat Sci 1, e127.

Lee, Y.H., Kuo, C.Y., Stark, J.M., Shih, H.M., and Ann, D.K. (2013). HP1 promotes tumor suppressor BRCA1 functions during the DNA damage response. Nucleic Acids Res 41, 5784-5798.

Lee, Y.H., Liu, X., Qiu, F., O'Connor, T.R., Yen, Y., and Ann, D.K. (2015). HP1beta is a biomarker for breast cancer prognosis and PARP inhibitor therapy. PLoS One 10, e0121207.

Lemaitre, C., and Soutoglou, E. (2014). Double strand break (DSB) repair in heterochromatin and heterochromatin proteins in DSB repair. DNA Repair (Amst) 19, 163-168.

Li, M.L., Jiang, Q., Bhanu, N.V., Wu, J., Li, W., Garcia, B.A., and Greenberg, R.A. (2018). Phosphorylation of TIP60 suppresses 53BP1 localization at DNA damage sites. Mol Cell Biol.

Lorkovic, Z.J., Park, C., Goiser, M., Jiang, D., Kurzbauer, M.T., Schlogelhofer, P., and Berger, F. (2017). Compartmentalization of DNA Damage Response between Heterochromatin and Euchromatin Is Mediated by Distinct H2A Histone Variants. Curr Biol 27, 1192-1199.

Luijsterburg, M.S., Dinant, C., Lans, H., Stap, J., Wiernasz, E., Lagerwerf, S., Warmerdam, D.O., Lindh, M., Brink, M.C., Dobrucki, J.W., et al. (2009). Heterochromatin protein 1 is recruited to various types of DNA damage. J Cell Biol 185, 577-586.

Mattoo, A.R., Pandita, R.K., Chakraborty, S., Charaka, V., Mujoo, K., Hunt, C.R., and Pandita, T.K. (2017). MCL-1 Depletion Impairs DNA Double-Strand Break Repair and Reinitiation of Stalled DNA Replication Forks. Mol Cell Biol 37.

McGinty, R.K., Henrici, R.C., and Tan, S. (2014). Crystal structure of the PRC1 ubiquitylation module bound to the nucleosome. Nature 514, 591-596. 
Mendez-Acuna, L., Di Tomaso, M.V., Palitti, F., and Martinez-Lopez, W. (2010). Histone post-translational modifications in DNA damage response. Cytogenet Genome Res 128, 28-36.

Mujoo, K., Pandita, R.K., Tiwari, A., Charaka, V., Chakraborty, S., Singh, D.K., Hambarde, S., Hittelman, W.N., Horikoshi, N., Hunt, C.R., et al. (2017). Differentiation of Human Induced Pluripotent or Embryonic Stem Cells Decreases the DNA Damage Repair by Homologous Recombination. Stem Cell Reports 9, 1660-1674.

Munoz, M.C., Yanez, D.A., and Stark, J.M. (2014). An RNF168 fragment defective for focal accumulation at DNA damage is proficient for inhibition of homologous recombination in BRCA1 deficient cells. Nucleic Acids Res 42, 7720-7733.

Nakatani, Y., Tagami, H., and Shestakova, E. (2006). How is epigenetic information on chromatin inherited after DNA replication? Ernst Schering Res Found Workshop, 89-96.

Pandita, T.K., and Richardson, C. (2009). Chromatin remodeling finds its place in the DNA double-strand break response. Nucleic Acids Res 37, 1363-1377.

Patel, N., Garikapati, K.R., Pandita, R.K., Singh, D.K., Pandita, T.K., Bhadra, U., and Bhadra, M.P. (2017). miR-15a/miR-16 down-regulates BMl1, impacting UbH2A mediated DNA repair and breast cancer cell sensitivity to doxorubicin. Sci Rep 7, 4263.

Pettersen, E.F., Goddard, T.D., Huang, C.C., Couch, G.S., Greenblatt, D.M., Meng, E.C., and Ferrin, T.E. (2004). UCSF Chimera--a visualization system for exploratory research and analysis. J Comput Chem 25, 1605-1612.

Rossi, A., Ferrari, K.J., Piunti, A., Jammula, S., Chiacchiera, F., Mazzarella, L., Scelfo, A., Pelicci, P.G., and Pasini, D. (2016). Maintenance of leukemic cell identity by the activity of the Polycomb complex PRC1 in mice. Sci Adv 2, e1600972.

Scully, R., and Xie, A. (2013). Double strand break repair functions of histone H2AX. Mutat Res 750, 5-14.

Serizay, J., and Ahringer, J. (2018). Genome organization at different scales: nature, formation and function. Curr Opin Cell Biol 52, 145-153.

Sharma, G.G., Hwang, K.K., Pandita, R.K., Gupta, A., Dhar, S., Parenteau, J., Agarwal, M., Worman, H.J., Wellinger, R.J., and Pandita, T.K. (2003). Human heterochromatin protein 1 isoforms HP1(Hsalpha) and HP1(Hsbeta) interfere with hTERT-telomere interactions and correlate with changes in cell growth and response to ionizing radiation. Mol Cell Biol 23, 8363-8376.

Shibata, A., Moiani, D., Arvai, A.S., Perry, J., Harding, S.M., Genois, M.M., Maity, R., van Rossum-Fikkert, S., Kertokalio, A., Romoli, F., et al. (2014). DNA doublestrand break repair pathway choice is directed by distinct MRE11 nuclease activities. Mol Cell 53, 7-18.

Shima, H., Suzuki, H., Sun, J., Kono, K., Shi, L., Kinomura, A., Horikoshi, Y., Ikura, T., Ikura, M., Kanaar, R., et al. (2013). Activation of the SUMO modification system is required for the accumulation of RAD51 at sites of DNA damage. J Cell Sci 126, 5284-5292.

Singh, D.K., Pandita, R.K., Singh, M., Chakraborty, S., Hambarde, S., Ramnarain, D., Charaka, V., Ahmed, K.M., Hunt, C.R., and Pandita, T.K. (2018). MOF 
Suppresses Replication Stress and Contributes to Resolution of Stalled Replication Forks. Mol Cell Biol 38.

Singh, H., Sekinger, E.A., and Gross, D.S. (2000). Chromatin and cancer: causes and consequences. J Cell Biochem Suppl Suppl 35, 61-68.

Svobodova Kovarikova, A., Legartova, S., Krejci, J., and Bartova, E. (2018). H3K9me3 and H4K20me3 represent the epigenetic landscape for 53BP1 binding to DNA lesions. Aging (Albany NY) 10, 2585-2605.

Ward, I.M., Minn, K., van Deursen, J., and Chen, J. (2003). p53 Binding protein $53 \mathrm{BP} 1$ is required for DNA damage responses and tumor suppression in mice. Mol Cell Biol 23, 2556-2563.

Wei, S., Li, C., Yin, Z., Wen, J., Meng, H., Xue, L., and Wang, J. (2018). Histone methylation in DNA repair and clinical practice: new findings during the past 5years. J Cancer 9, 2072-2081.

White, D., Rafalska-Metcalf, I.U., Ivanov, A.V., Corsinotti, A., Peng, H., Lee, S.C., Trono, D., Janicki, S.M., and Rauscher, F.J., 3rd (2012). The ATM substrate KAP1 controls DNA repair in heterochromatin: regulation by HP1 proteins and serine 473/824 phosphorylation. Mol Cancer Res 10, 401-414.

Williams, J.S., Williams, R.S., Dovey, C.L., Guenther, G., Tainer, J.A., and Russell, P. (2010). gammaH2A binds Brc1 to maintain genome integrity during S-phase. EMBO J 29, 1136-1148.

Wood, L.D., Halvorsen, T.L., Dhar, S., Baur, J.A., Pandita, R.K., Wright, W.E., Hande, M.P., Calaf, G., Hei, T.K., Levine, F., et al. (2001). Characterization of ataxia telangiectasia fibroblasts with extended life-span through telomerase expression. Oncogene 20, 278-288.

Xie, A., Odate, S., Chandramouly, G., and Scully, R. (2010). H2AX posttranslational modifications in the ionizing radiation response and homologous recombination. Cell Cycle 9, 3602-3610.

Yang, J., Anishchenko, I., Park, H., Peng, Z., Ovchinnikov, S., and Baker, D. (2020). Improved protein structure prediction using predicted interresidue orientations. Proc Natl Acad Sci U S A 117, 1496-1503.

Yuan, J., and Chen, J. (2010). MRE11-RAD50-NBS1 complex dictates DNA repair independent of H2AX. J Biol Chem 285, 1097-1104.

Zeng, W., Ball, A.R., Jr., and Yokomori, K. (2010). HP1: heterochromatin binding proteins working the genome. Epigenetics 5, 287-292.

Zhao, S., Allis, C.D., and Wang, G.G. (2021). The language of chromatin modification in human cancers. Nat Rev Cancer 21, 413-430.

Zhou, Y., Caron, P., Legube, G., and Paull, T.T. (2014). Quantitation of DNA double-strand break resection intermediates in human cells. Nucleic Acids Res 42, e19.

Zhu, Q., Pao, G.M., Huynh, A.M., Suh, H., Tonnu, N., Nederlof, P.M., Gage, F.H., and Verma, I.M. (2011). BRCA1 tumour suppression occurs via heterochromatinmediated silencing. Nature 477, 179-184. 


\section{Figure legends}

Fig. 1. The HP1 $\beta$ chromo shadow domain (CSD) contributes to HR mediated repair of IR-induced DNA damage and cell survival. A) Map of HP1 $\beta$ showing the chromo domain (20 aa-72 aa), hinge region (72 aa - 110 aa) and chromo shadow domain (110aa- 180aa). HP1 $\beta$ mutant CD HP1 $\beta$ was generated by deleting amino acids 117 to 185 and CSD HP1 $\beta$ was generated by deleting amino acids 22 to 79 from HP1 $\beta$. B) Transfected HP1 $\beta$ gene expression in $\mathrm{H} 1299$ cells after endogenous HP1 $\beta$ depletion with a 3' UTR- HP1 $\beta$ siRNA (pCDNA3.1 FLAG HP1 $\beta$, pCDNA3.1 FLAG CD HP1 $\beta$, pCDNA3.1 FLAG CSD HP1 $\beta$ ). Cellular extracts are prepared $48 \mathrm{hr}$ after transfection and FLAG HP1 $1 \beta$, CD HP1 $\beta$, CSD HP1 $\beta$ determined by western blotting. C) Cell survival after increasing IR doses of HP1 $\beta$ depleted cells, ectopically expressing Flag HP1 $\beta$, CD HP1 $\beta$, or CSD HP1 $\beta$ as measured by colony formation assay D) Delayed resolution of IR-induced (2Gy) $\mathrm{Y}-\mathrm{H} 2 \mathrm{AX}$ foci, detected by immuno fluorescent staining, in HP1 $\beta$ depleted $\mathrm{H} 1299$ cells is rescued by Flag HP1 $\beta$ or CSD but not CD HP1 $1 \beta$ expression. E) Dissolution of IR-induced, 53BP1 foci is delayed by HP1 $\beta$ depletion and restored by ectopic Flag HP1 $\beta$ or CSD expression F) Defective HR repair in HP1 $\beta$ depleted DR-GFP cells is restored by ectopic Flag HP1 $1 \beta$ or CSD expression G) HP1 $\beta$ depletion does not affect DNA DSB repair by NHEJ as measured in Ch1B-EJ5 cells. All standard deviations were calculated from three independent experiments. ${ }^{* *} p<0.01 ;{ }^{* *} p<$ 0.001 . 
Fig. 2. CSD HP1 $\beta$ is recruited to DSB sites through CAF1. A) Increased HP1 $\beta$ recruitment to break sites as measured by ChIP/qPCR at different I-Sce1 induced cleavage sites. B) Depletion of HP1 $\beta$ does not alter DSB induction as measured by $\gamma-H 2 A X$ ChIP/qPCR at different ISce1 sites .C\&D) Flag CD HP1 $\beta$ and Flag CSD HP1 $1 \beta$ recruited to Chr1A and Chr1B DSB sites. Using ChIP-q PCR, CD HP1 $\beta$ and CSD HP1 $1 \beta$ recruitment was determined. E) CAF1 and KAP1 coimmunoprecipitated with Flag HP1 $1 \beta$ and CSD HP1 $\beta$. F) CAF1 deletion decreases CSD HP1 $\beta$ and Flag HP1 $\beta$ recruitment at the Chr1A DSB site. G) CAF1 depletion blocks CSD mediated rescue of irradiated HP1 $1 \beta$ depleted cells as determined by clonogenic cell survival assay. $\mathrm{H}$ ) Depletion of CAF1 blocks CSD mediated rescue of homologous recombination in HP1 $\beta$ depleted cells as determined by DR-GFP assay. All standard deviations were calculated form at least three independent experiments. ${ }^{*} p<0.05 ;{ }^{* *} p<0.01 ;{ }^{* * *} p<0.001$.

Fig. 3. DNA resection at DSBs, Rad51 foci formation and HR repair in HP1 $\beta$ depleted cells are rescued by CSD HP1 $\beta$ expression. A) Decreased SSDNA generated at DSBs in HP1 $\beta$ depleted cells as measured at the $335 \mathrm{bp}$ and 1618 bp after DSB induction with tamoxifen. Amount of after resection was measured at 335 and $1618 \mathrm{bp} \mathrm{3'}$ ' from the DSB site using two different primer sets for qPCR. SD values were determined in between three independent experiments. ${ }^{*} p<0.05$; ${ }^{* *} p<0.01 ;{ }^{* *} p<0.001$. B) Single strand DNA formation at a DSB in HP1 $\beta$ depleted cells ectopically expressing CD HP1 $1 \beta$ or CSD HP1 $\beta$ was measured proximal and distal to the site by qPCR using the ER-AsiSI system as described in Material and Methods. C) Western blot showing knockdown of CAF1 and CtIP by 
specific siRNA. D)Percentage of single strand DNA formed in CSD-HP1 $\beta$ expressing cells was quantitated in presence and absence of CAF1. E) RAD51 foci formation in irradiated HP1 $\beta$ depleted cells is restored by CSD but not CD expression. Approximately 300 cells with RAD51 foci were examined and standard deviation from three experiments was calculated. F) 53BP1 depletion does not rescue HP1 $\beta$ dependent DNA resection. ssDNA generated after resection was measured at proximal and distal sites to a DSB using QPCR in cells with and without. G) DR-GFP cells were transfected with respective siRNA's (Control siRNA, HP1 $\beta$ siRNA, 53BP1 siRNA, and CtIP siRNA) and after 48hr cells were retransfected with I-Sce1 plasmid. The percentage of GFP positive cells was measured by using FACS. Percentage of GFP positive cells was normalized to control cells. H) Cells with and without above-mentioned siRNA were enumerated for RAD51 foci after irradiation. The three independent experiments were performed and standard deviation between these experiments was calculated. ${ }^{*} p<0.05 ;{ }^{* *} p<0.01 ;{ }^{* *} p<0.001$

Fig. 4. CSD HP1 $\beta$ promotes BRCA1 recruitment at DSB sites. A) Immunofluorescent detection of BRCA1 and 53BP1 foci in irradiated, HP1 $\beta$ depleted H1299 cells expressing FLAG HP1 $\beta$ or FLAG domain mutants. Images were captured on an Axio-Vision Imager 2 microscope for analysis B) BRCA1 foci measured $6 \mathrm{~h}$ after irradiation in cells treated as in A. C) Co-immunostaining for 53BP1 and BRCA in post-irradiated fixed samples. Co-localized 53BP1: BRCA1 foci were counted in 3 sets of 50 cells, and the percent co-localized 53BP1/BRCA1 foci was calculated relative to total number of foci (53BP1 plus BRCA1). D) HP1 $\beta$ 
depletion decreases BRCA1 recruitment to DSB sites. BRCA1 levels at the Chr1A and Chr1B sites were measured by ChIP-qPCR before and 20h after I-Sce1 transfection. E\&F) BRCA1 recruitment at the Chr1A and Chr1B DSB sites was measured in HP1 $\beta$ depleted cells with or without FLAG CD HP1 1 (E) or FLAG CSD HP1ß $(F)$ expression. Standard deviations calculated from a minimum of three independent experiments. ${ }^{* *} p<0.01 ;{ }^{* * *} p<0.001$, Scale bar is $10 \mu \mathrm{m}$.

\section{Fig. 5. HP1 $\beta$ interacts with RING1A and enhances BRCA1 recruitment at DSB}

sites. A) Effect of ATM inhibition on clonogenic survival of irradiated cells. Cells were treated with $10 \mu \mathrm{M}$ ATM inhibitor (KU-55933) for $1 \mathrm{hr}$ before IR treatment. B) p-MDC1 foci formation/dissolution in irradiated H1299 cells is not altered by HP1 $\beta$ depletion. C) FLAG RING1A co-immunoprecipitated with HA HP1 $\beta$. D) Flag RING1A interaction with CD HP1 $\beta$ and CSD HP1 $\beta$ E) RING1A enrichment after DNA damage at Chr1A and Chr1B DSB sites as measured by ChIP-qPCR is decreased by HP1 $\beta$ depletion. F) Decreased single strand DNA formation at DSBs in RING1A or HP1 $\beta$ depleted cells as measured by the ER-AsiSI assay G) Impact of RING1A depletion on BRCA1 recruitment at Chr1A and Chr1C DSB sites before and after I-Sce1 transfection H) Effect of RING1A depletion on HR frequency in DR-GFP cells with and without HP1 $\beta$. Experiments were done for three times and Standard deviation was calculated. ${ }^{* *} p<0.01 ;{ }^{* * *} p<0.001$

Fig. 6. HP1 $\beta$ modulates H2A K119-ub levels at DSB sites. A\&B) HP1 $\beta$ depletion decreases H2A poly-ubiquitination. Control and HP1 $\beta$ depleted H1299 cells were transfected with FLAG-H2A vector then irradiated (10 Gy). FLAG immunoprecipitated H2A was analyzed for Ub by western blot analysis with Flag 
antibody. Relative H2A mono, polyubiquitination at individual time points $(0,0.5$, 1.5, 4 hrs) was calculated relative of total H2A. C) Effect of HP1 $\beta$ depletion on H2AK119-ub levels at the Chr1A and Chr1B sites before and after DSB induction as determined by ChIP-qPCR. D) H2A-ub reversal of radio sensitivity in HP1 depleted cells is independent of ATM. Cells with and without HP1 $1 \beta$ depletion were treated with ATM inhibitor (KU 55933) then treated with increasing IR doses. Effect of H2A-ub expression on cell survival was determined by clonogenic survival. E) Exogenous $\mathrm{H} 2 \mathrm{~A}-\mathrm{ub}$ partially restores $\mathrm{HR}$ in $\mathrm{HP} 1 \beta$ depleted cells as determined by the DR-GFP repair assay. Three independent experiments were conducted and an SD value in between experiments was determined. ${ }^{*} p<0.05 ;{ }^{* \star} p<0.01 ;{ }^{* \star *} p<$ 0.001

Fig. 7. Representative model of HP1 $\beta$ role in BRCA1 recruitment .

\section{Supplementary Fig. 1: HP1 $\beta$ deletion mutants graphical representation and}

its DNA damage response: (A\&B) Immuno fluorescent images of $\mathrm{Y}-\mathrm{H} 2 \mathrm{AX}$ and 53BP1 foci at different times after irradiation (2Gy). Scale bar shown here is $20 \mu \mathrm{m}$. Cell were depleted of endogenous HP1 $\beta$ with siRNA then transfected with the indicted FLAG tagged HP1 $\beta$ expression vectors before irradiation. C) Nonhomologous end joining DNA repair as measured by the pimEJ5 plasmid assay in HP1 $\beta$ depleted cells supplemented with full length or HP1 $\beta$ deletion mutants. 3 individual experiments were conducted and an SD value in between experiments was determined. 
Supplementary Fig. 2: HP1 $\beta$ mutant recruitment to DSB sites in independent of KAP1.

A) I-Sce1 containing unique sites in gene-rich and -poor regions of human chromosomes. B) Enrichment of $\mathrm{H} 3 \mathrm{~K} 9 \mathrm{me} 2$ levels after I-Scel inducible DNA DSBs. C) Full length HP1 $\beta$ and its mutant $(C D H P 1 \beta$ and CSDHP1 $\beta$ coimmunoprecipitation analysis with CAF1 and KAP1. D) Homologous Recombination in CSD HP1 $1 \beta$ expressing cells after KAP1 depletion measured by DR-GFP assay. Three to four independent experiments were carried out, SD values was determined. ${ }^{*} p<0.05 ;{ }^{* *} p<0.01 ;{ }^{* * *} p<0.001$.

Supplementary Fig. 3: DNA end resection associated repair foci formation in irradiated HP1 $\beta$ depleted cells expressing deletion mutants: A) Western blot showing the depletion of HP1 $\beta, 53 \mathrm{BP} 1$ and CtIP with specific siRNAs. B\&C) Immuno fluorescent visualization of RAD51 foci in different samples as described in Fig. 3 with and without Irradiation (10Gy). Scale bar shown here is $20 \mu \mathrm{m}$. D) 53BP1 and RIF1 foci formation after 4 hrs of post Irradiation in HP1 $\beta$ depleted cells expressing either the CD or CSD HP1 $\beta$. Scale bar is $10 \mu \mathrm{m}$.

Supplementary Fig. 4: HP1 $\beta$ depletion has no impact on the ATM mediated DNA damage response. A) Western blot showing depletion of HP1b with specific siRNA in GM5823+hTERT cells. B) Clonogenic cell survival after IR exposure of GM5823+hTERT cells with and without HP1 depletion. B\&C) Western blot analysis of cells with and without HP1 $\beta$ irradiated with $10 \mathrm{~Gy}$. Cell lysates were prepared 0 , 30, 60,120 mins after radiation. D) Cells with and without HP1 $\beta$ were immuno 
stained for p-MDC1 after radiation. Scale bar is $20 \mu \mathrm{m}$. Three independent experiments were carried out and SD values determined. $p<0.05 ;{ }^{* *} p<0.01$.

\section{Supplementary Fig.5: HP1 $\beta$ interaction with PRC1 complex protein after} irradiation and Model of RING1A and CSD HP1 $\beta$ interaction. A) Coimmunoprecipitation analysis of endogenous RING1A and 1B with Flag HP1 $\beta$, with and without irradiation). B) Invitro pull-down of recombinantly purified RING1A and CSD HP1 $\beta$ proteins; top, Coomassie gel; bottom, western blot. C) Rigid-body docking model of HP1 (80-185aa) with FL-RING1A. Zn ions are shown in gray spheres. D\&E) Sequence conservations are mapped onto RING1A and HP1 $\beta$ models. The CD HP1 $\beta$ model is aligned over the CSD HP1 $\beta$ docking model. The potential interaction residues between RING1A and CSD HP1 $\beta$ are labelled. 
\begin{tabular}{lllllll}
1 & 1 & 20 & 72 & 110 & 180 & 185 \\
\hline & & & & & &
\end{tabular}

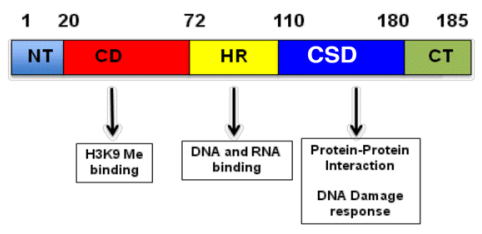

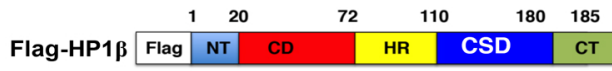

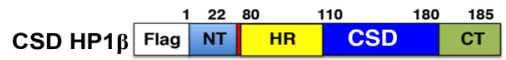

\begin{tabular}{l|l|lllll} 
& \multicolumn{1}{c}{1} & 20 & 72 & 110 & 117 \\
CD HP1/ & Flag & NT & CD & & HR & \\
\hline
\end{tabular}
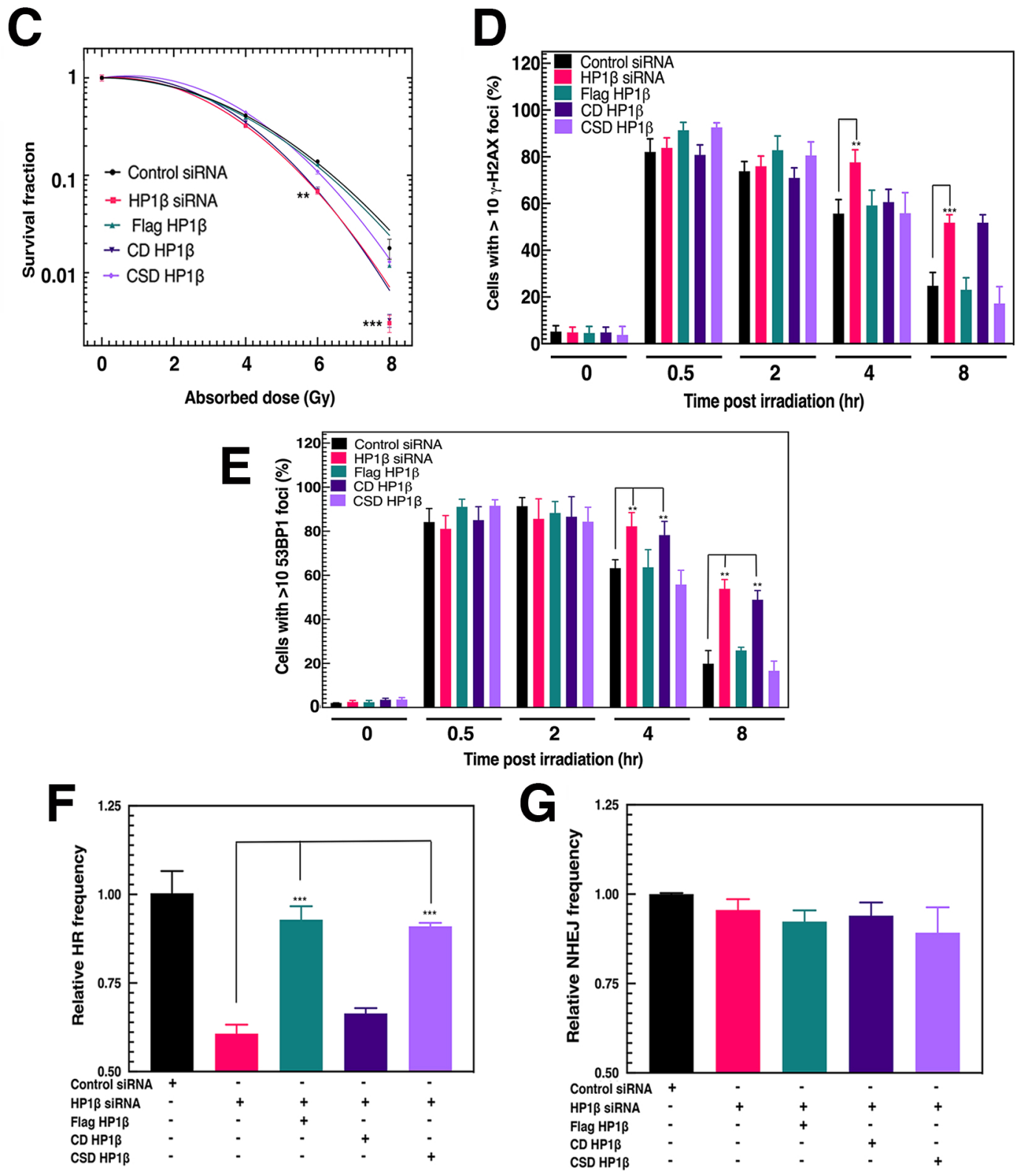
(A)

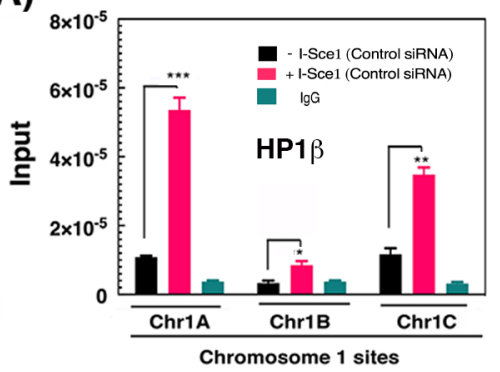

(C)

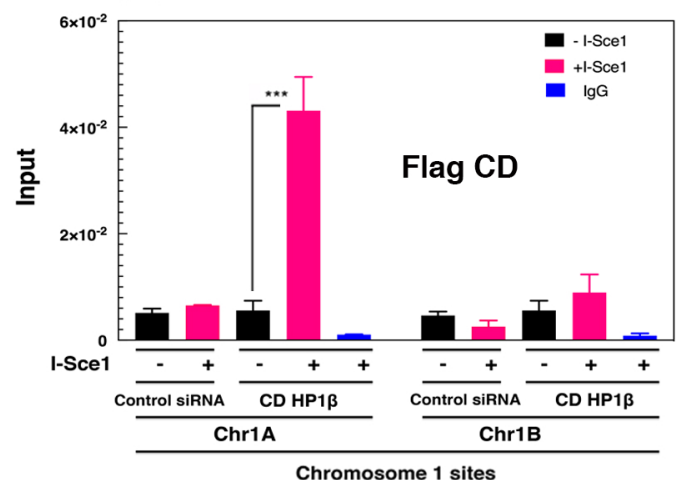

(E)

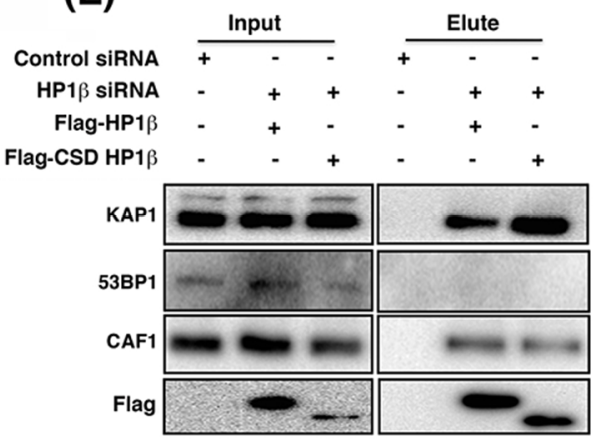

(G)

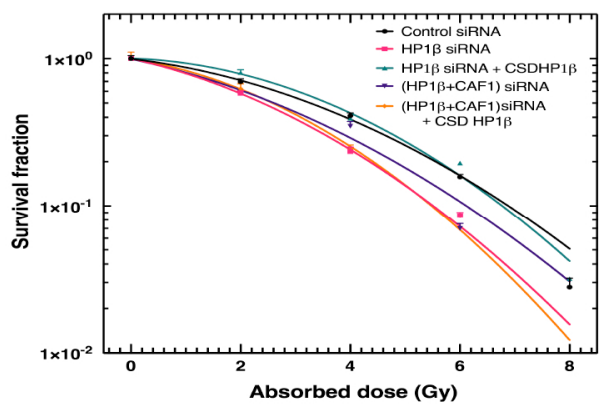

(B)

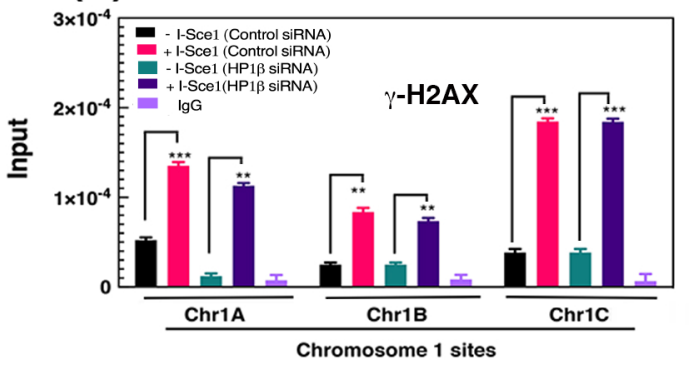

(D)
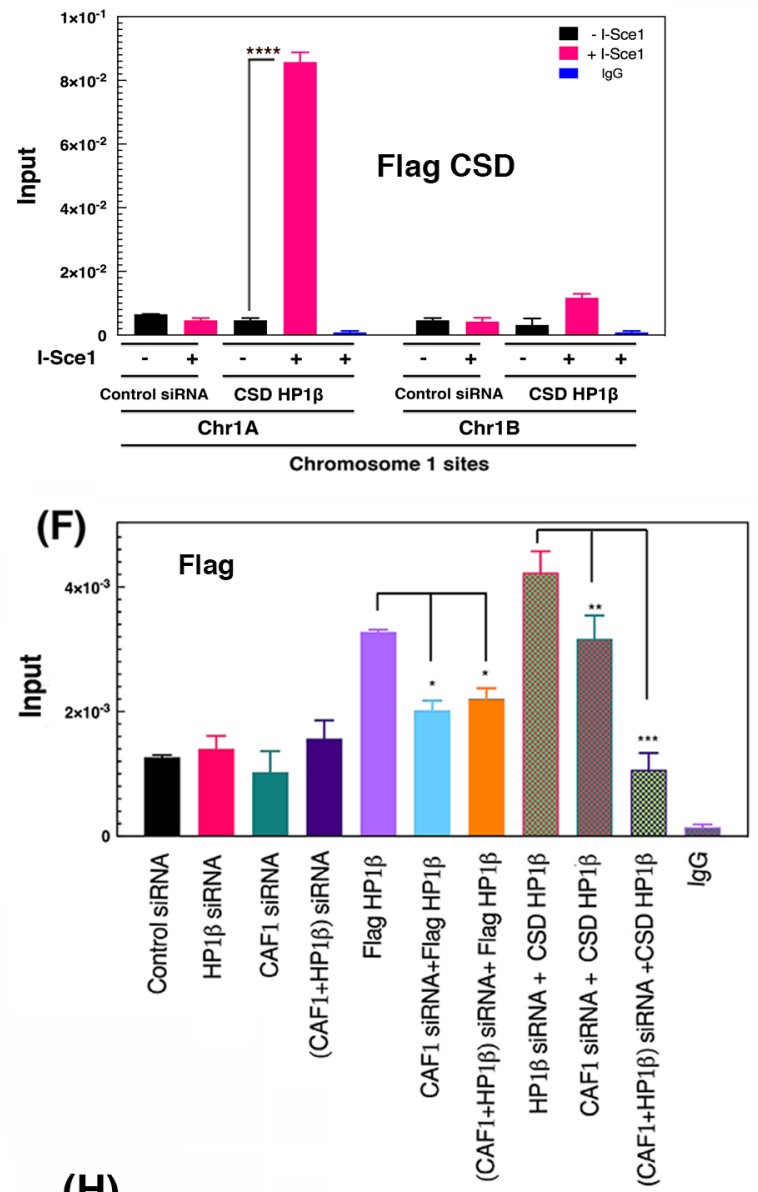

(H)

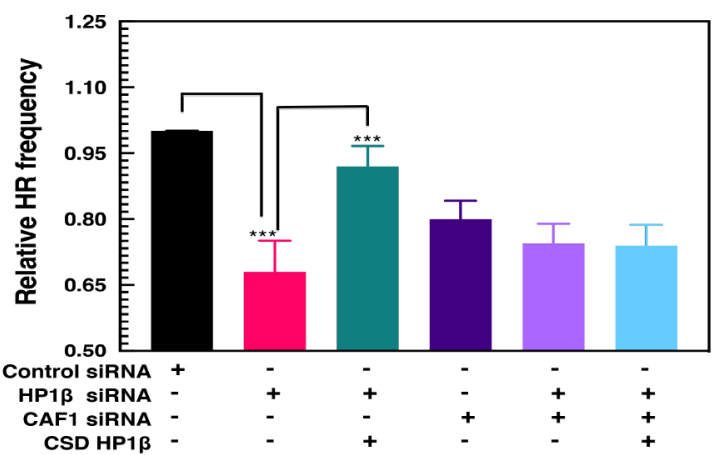


A

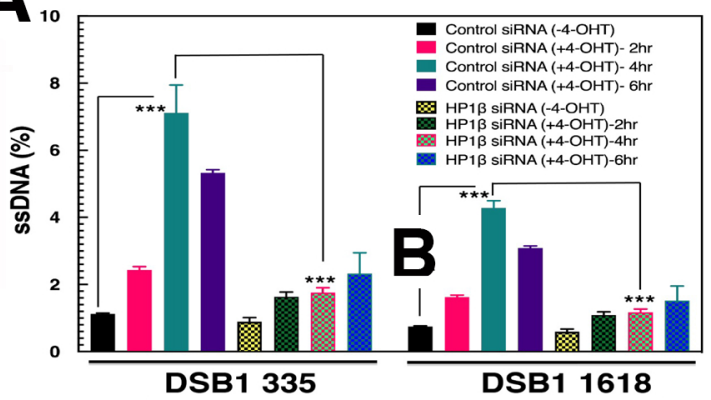

Nucleotide start position

C

Control siRNA +

53BP1 SIRNA -

CtIP SiRNA -

HP1 $\beta$ SIRNA -

53BP1

CtIP

HP1 $\beta$

GAPDH

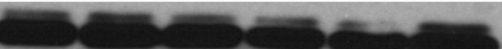



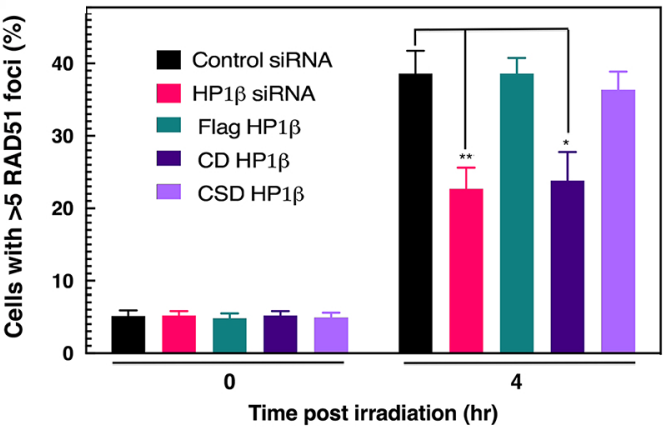

G

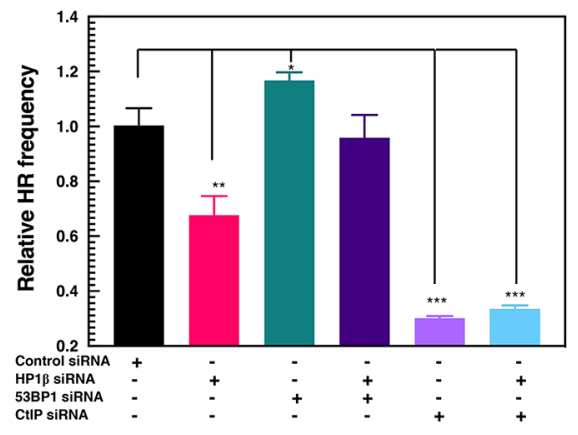

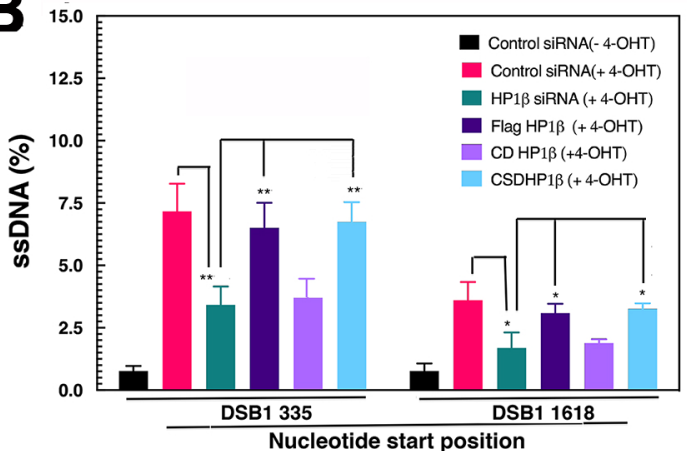

D
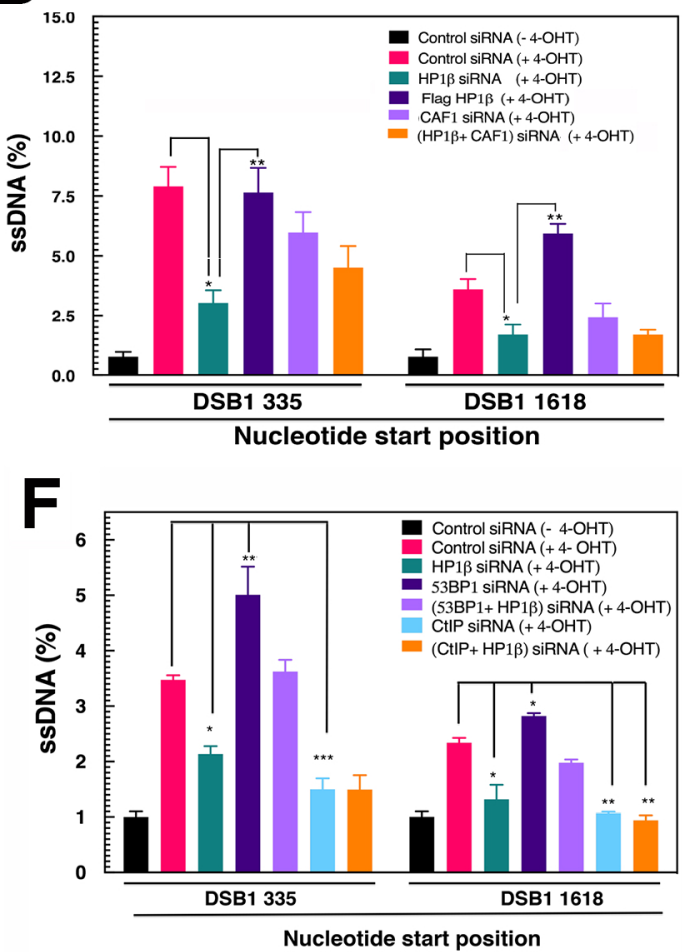

4

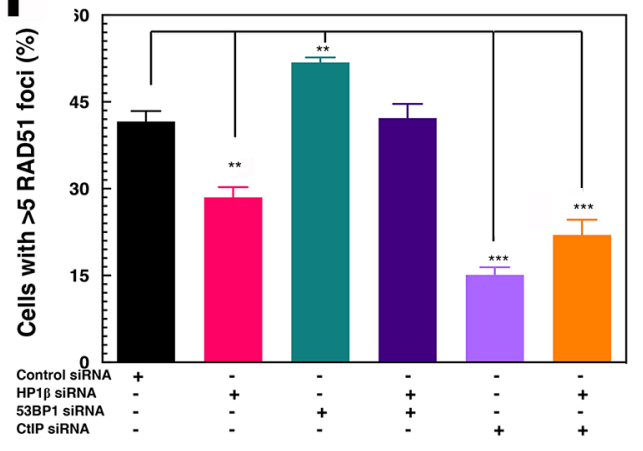




\section{Fig 4}

(A)

Control siRnA

HP1 $\beta$ siRNA

Flag-HP1 $\beta$

CD HP1 $\beta$

CSD HP1 $\beta$

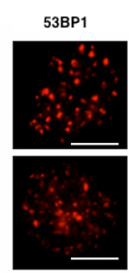

BRCA1
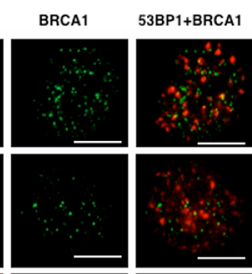

DAPIt
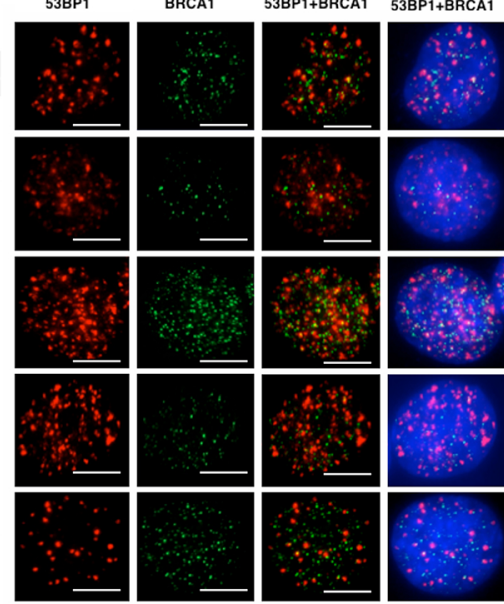

(B)

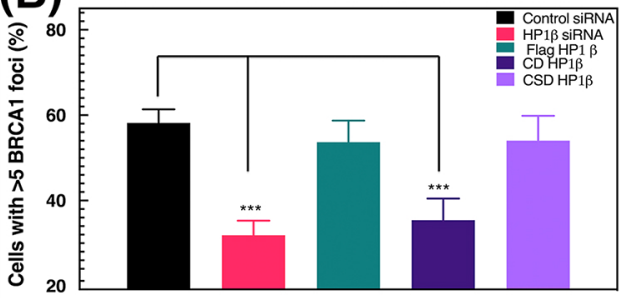

(C)

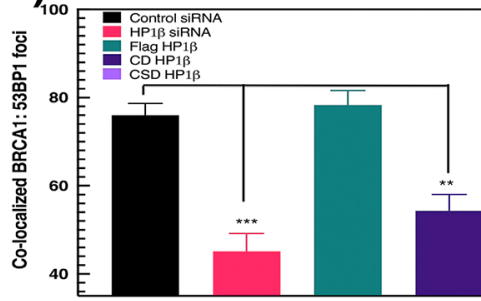

(D)

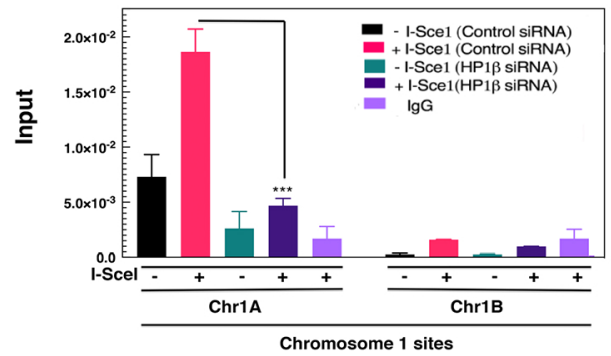

(E)

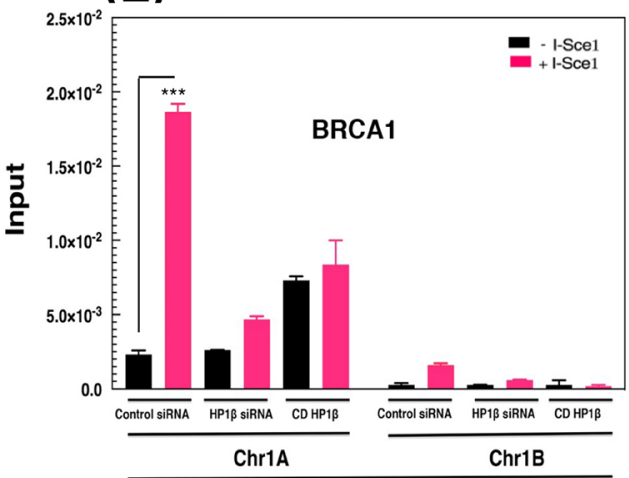

Chromosome 1 sites
(F)

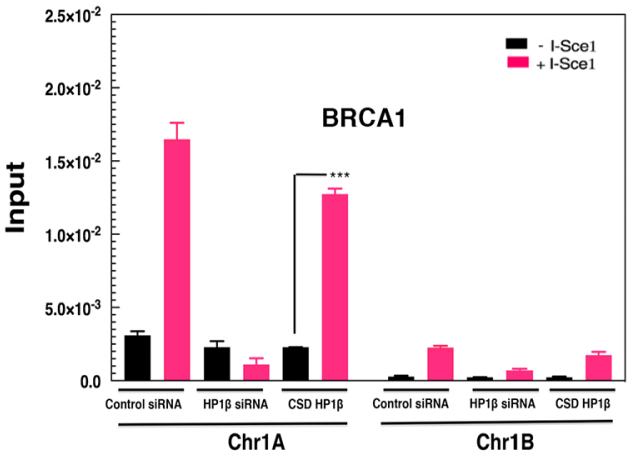

Chromosome 1 sites 
(A)
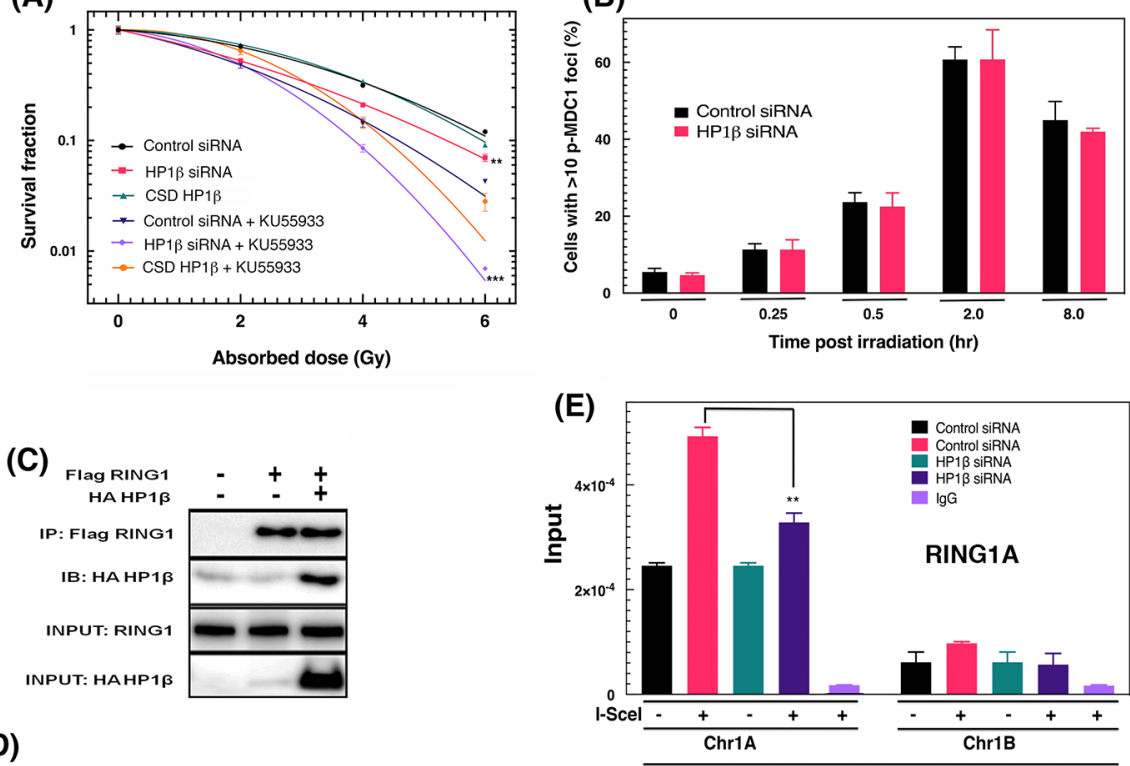

(C)

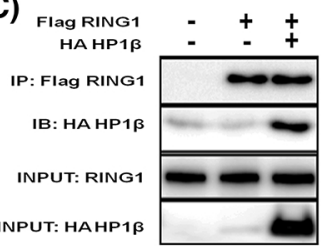

(D)
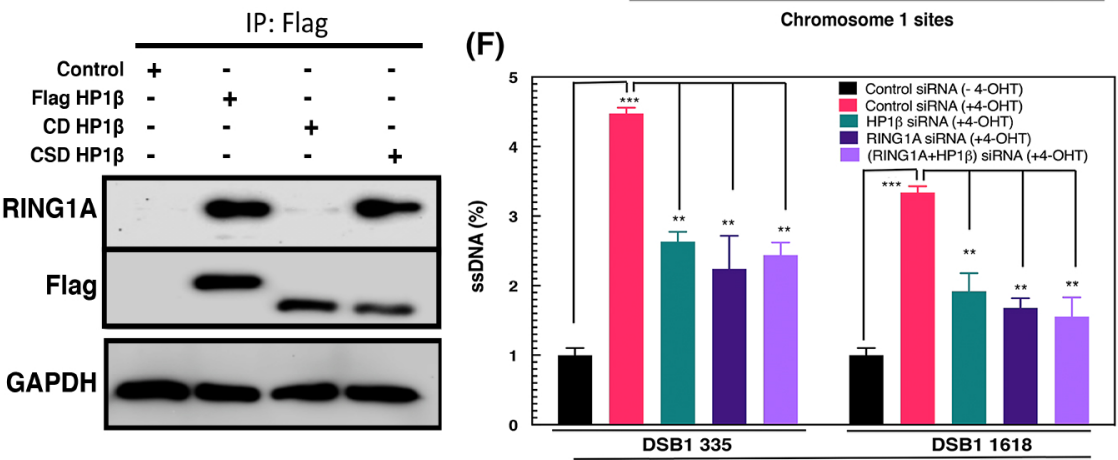

Nucleotide start position

\section{(G)}

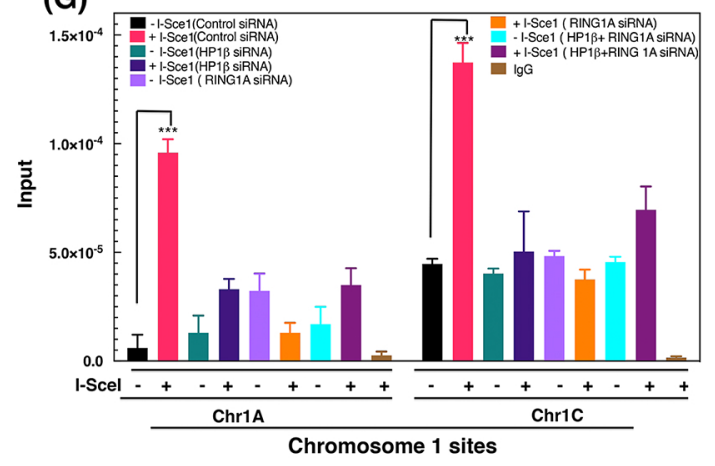

(H)

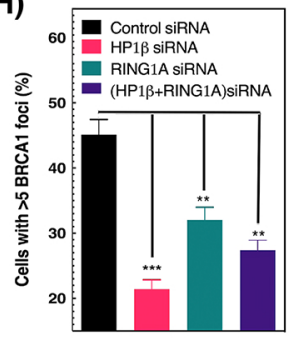


(A)

Fig6

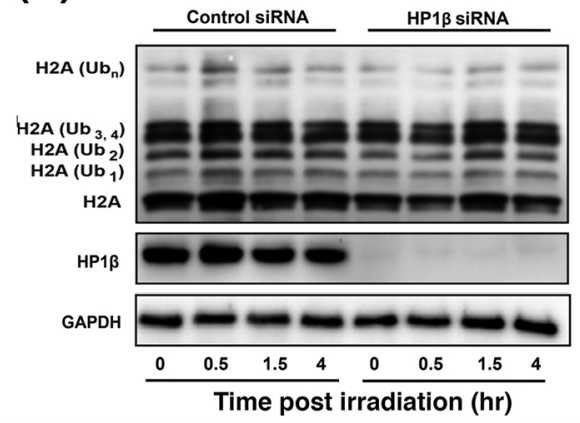

(B)

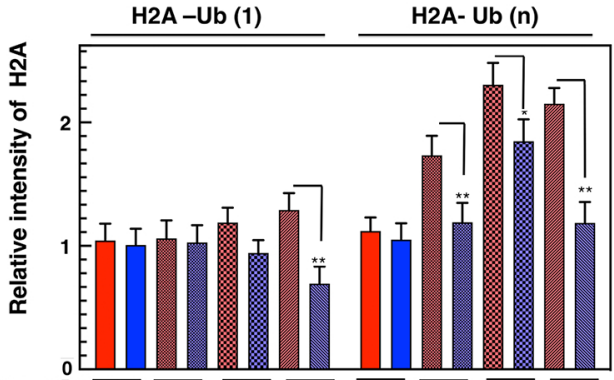

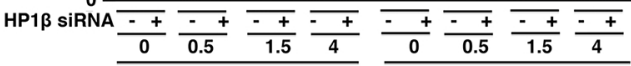

Time post irradiation (hr)

(C)

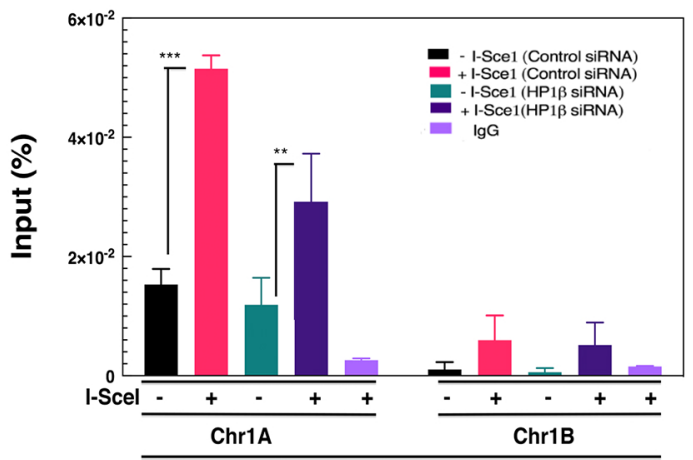

Chromosome 1 sites

(D)

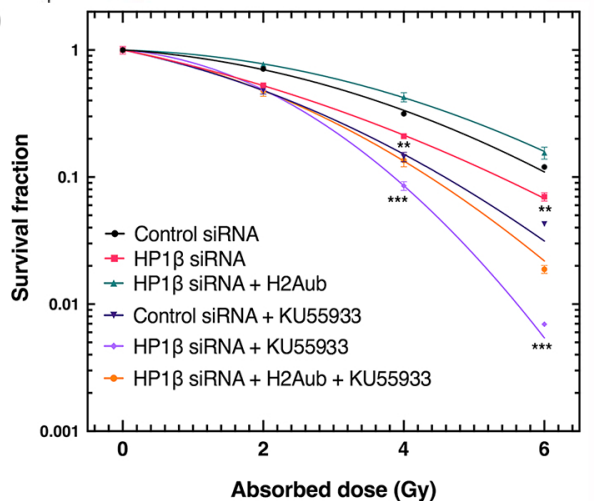

(E)

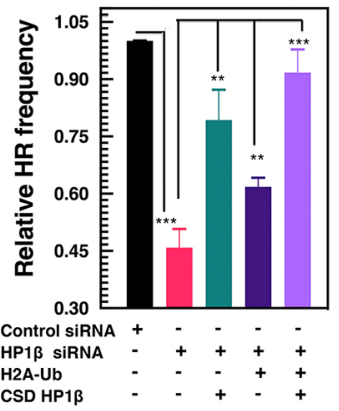



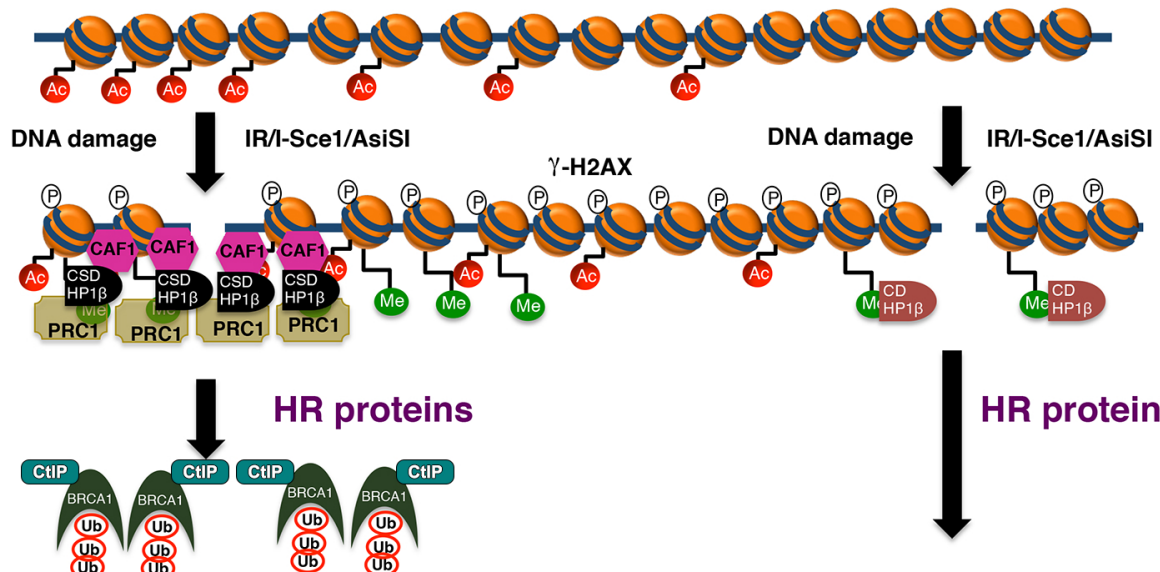

HR proteins
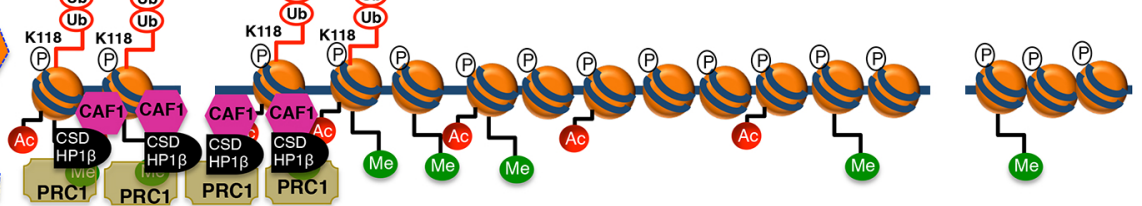

$\sqrt{\text { High }}$

High HR

Low HR

Low

Resection 


\section{Supplementary Fig. 1}

(A)

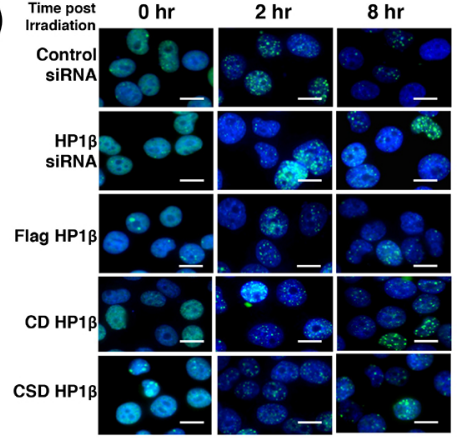

(C)

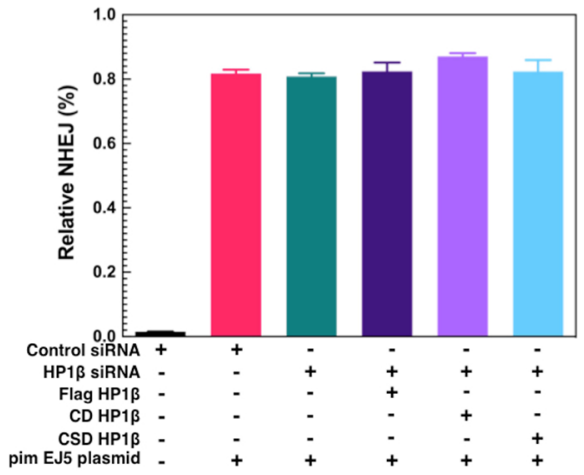

(B)

Time post Irradiation

$0 \mathrm{hr}$
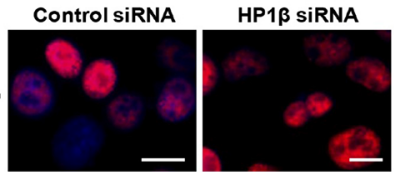

$8 \mathrm{hr}$
Flag-HP1 $\beta$

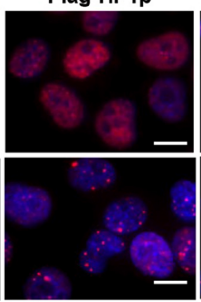

CD HP1 $\beta$

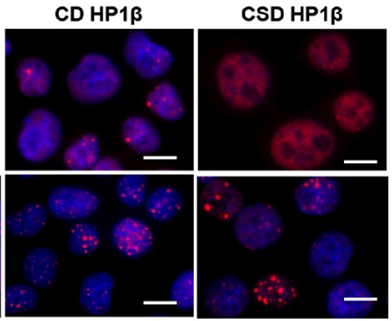




\section{Supplementary Fig. 2}

A
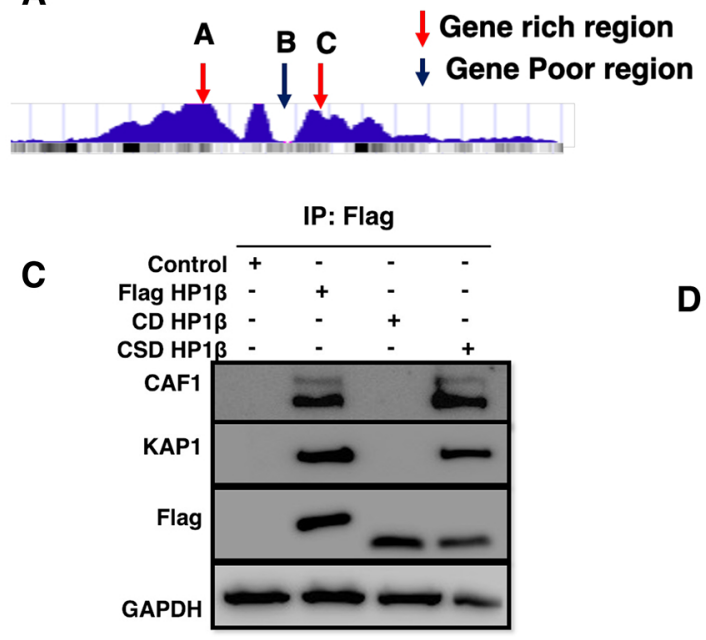

B

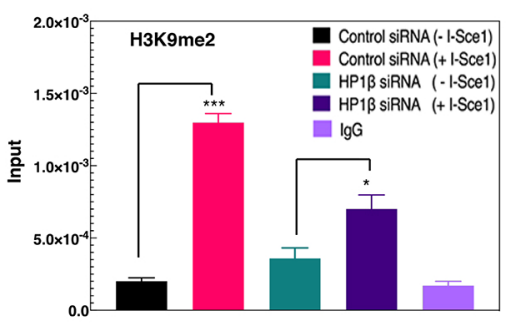

D

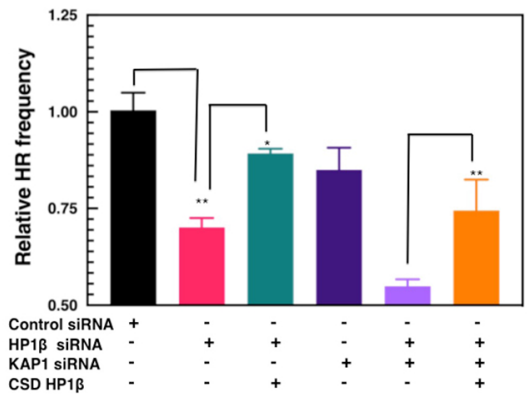




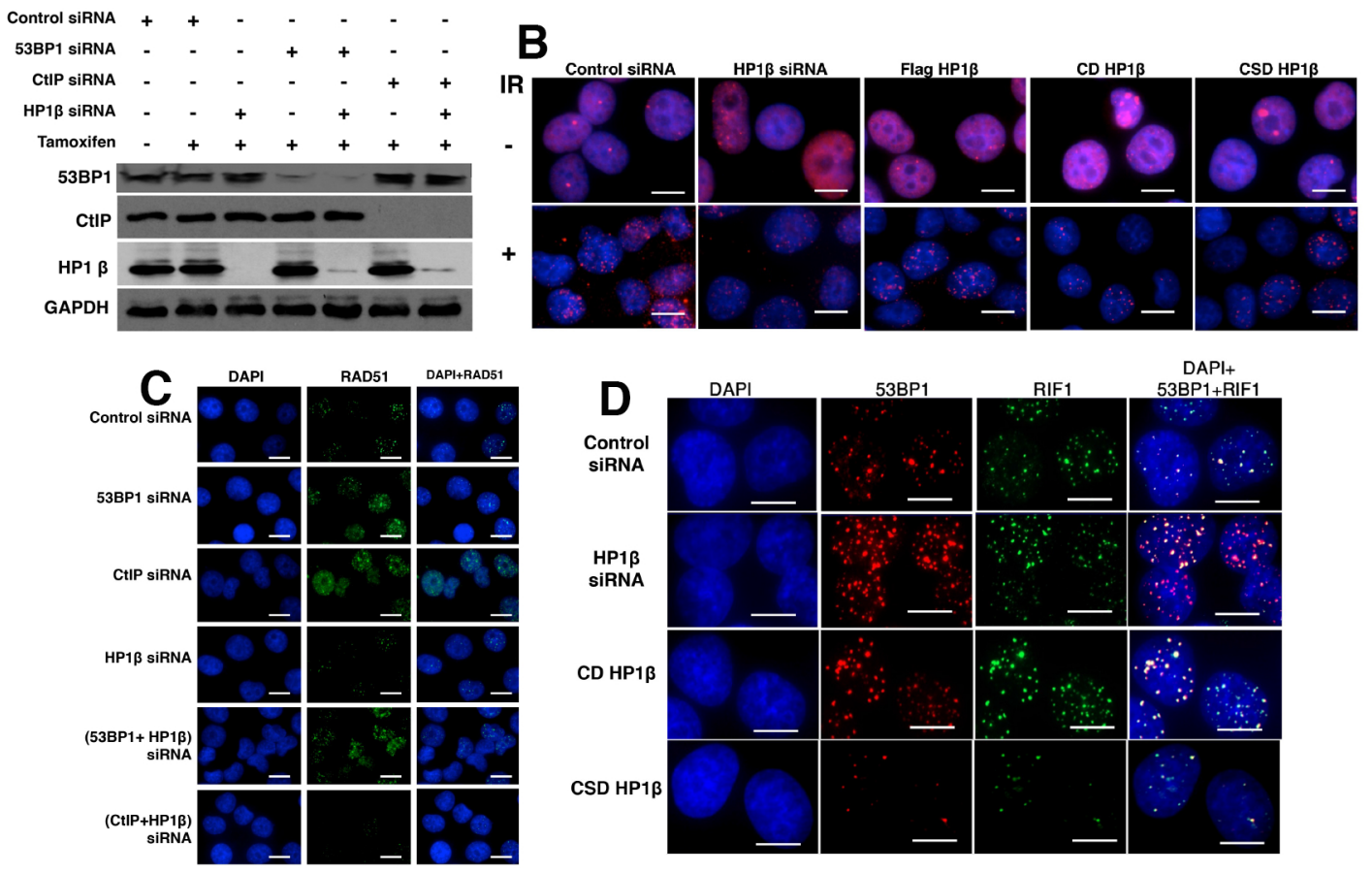


Supplementray Fig. 4
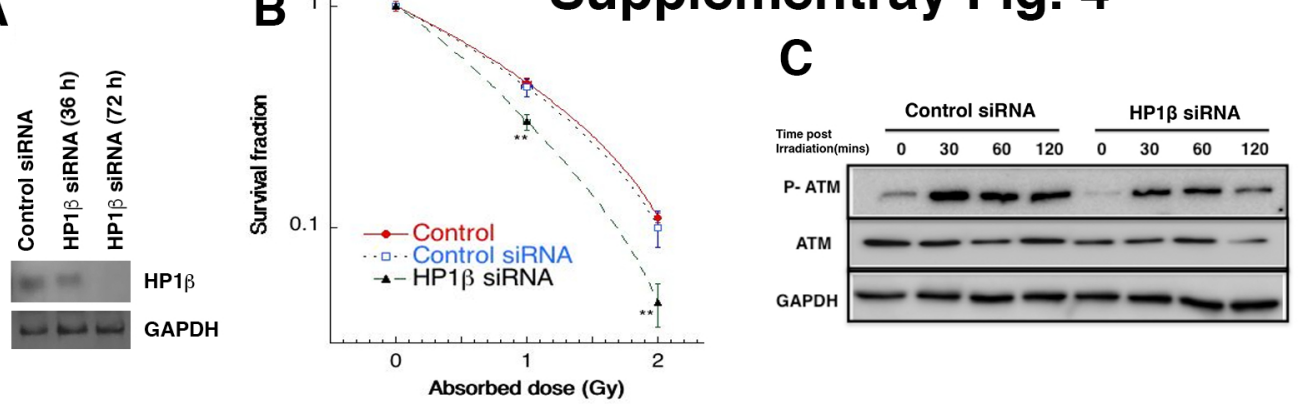

D

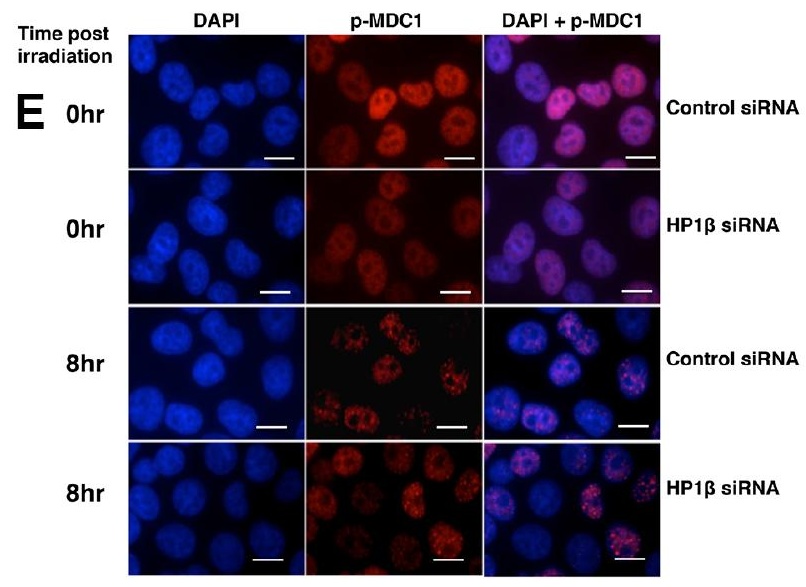




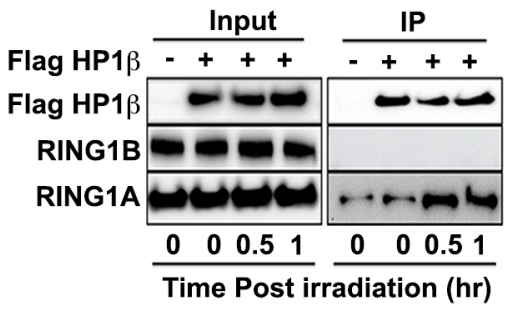

B

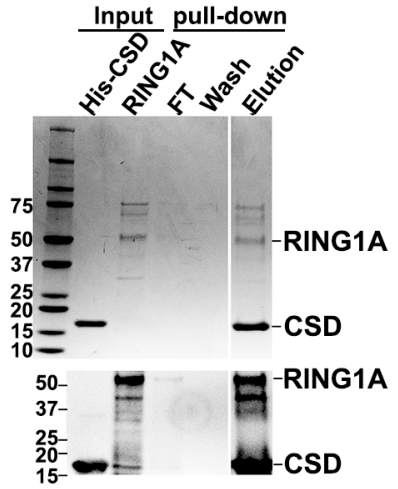

C
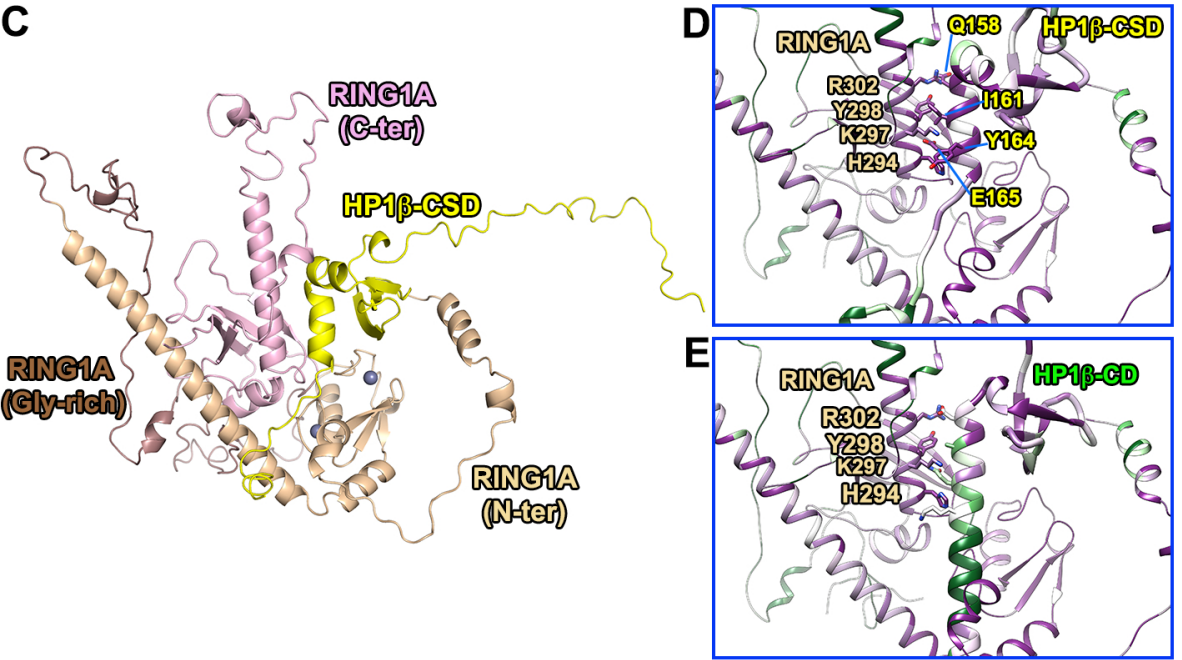

Conservation 